\title{
LO QUE UN EPITAFIO ESCONDE: PEDRO PÉREZ, OBISPO DE SALAMANCA (1248-1264)*
}

\author{
POR \\ FERNANDO GUTIÉRREZ BAÑOS ${ }^{3}$ \\ Universidad de Valladolid \\ Y \\ ESTRELLA PÉREZ RODRÍGUeZ ${ }^{4}$ \\ Universidad de Valladolid
}

\section{RESUMEN}

La capilla de San Martín de la Catedral vieja de Salamanca alberga un sepulcro identificado por un epitafio como perteneciente al obispo del siglo XIII Pedro Pérez. Esta inscripción es un poema latino que ensalza las virtudes del prelado a través de topoi que no revelan datos reales sobre su vida: de hecho, nuestro conocimiento de Pedro Pérez aún se basa en el trabajo de los eruditos de los siglos XVII y XVIII. El propósito de este artículo es, por una parte, editar y analizar el epitafio como ejemplo destacado de la poesía latina de su tiempo y, por otra parte, explorar, a través de documentos, la vida y carrera de este individuo tan interesante, fundador, muy probablemente, de la capilla de San Martín y, como tal, responsable de su decoración original, de la que aún subsisten pinturas murales.

Palabras Clave: Pedro Pérez; episcopologio de Salamanca; Catedral vieja de Salamanca; epigrafía medieval; poesía latina medieval.

\section{WHAT LIES BEHIND AN EPITAPH: PEDRO PÉREZ, BISHOP OF SALAMANCA}

\section{(1248-1264)}

\section{ABSTRACT}

The chapel of St Martin of the Old Cathedral of Salamanca houses a tomb identified by an epitaph as belonging to the thirteenth-century bishop Pedro Pérez. This inscription is a Latin poem praising the virtues of the prelate through topoi that reveal no real data about his life: in fact, our knowledge of Pedro Pérez still relies on the work of scholars of the $17^{\text {th }}$ and $18^{\text {th }}$ centuries. The aim of this article is, on the one hand, editing and analysing the epitaph as an outstanding example of the Latin poetry of its age and, on the other hand, studying, through records, the life and career of this very interesting personage, quite probably the founder of the chapel of St Martin and, if so, the person responsible for its original decoration, from which wall paintings still survive.

KEY WORDS: Pedro Pérez; episcopology of Salamanca; Old Cathedral of Salamanca; Medieval epigraphy; Medieval Latin poetry.

Cómo CitAR este ARtículo / CitATION: Gutiérrez Baños, F. y Pérez Rodríguez, E. 2019. «Lo que un epitafio esconde: Pedro Pérez, obispo de Salamanca (1248-1264)». Hispania Sacra 71, 143: 59-76. https://doi.org/10.3989/hs.2019.004

Recibido/Received 16-01-2017

Aceptado/Accepted 12-03-2017

\footnotetext{
*Proyecto de investigación Retablos-tabernáculo de la Baja Edad Media en la Corona de Castilla: estudio, documentación y difusión: HAR201782949-P (MINECO/AEI/FEDER; UE); G.I.R. de la Universidad de Valladolid IDINTAR: Identidad e intercambios artísticos. De la Edad Media al mundo contemporáneo. Proyecto de investigación Lexicon Latinitatis Medii Aevi Castellae et Legionis (s. VIII-1230): FFI2015-64340-P (MINECO/FEDER) y VA (Junta de Castilla y León); G.I.R. de la Universidad de Valladolid León y Castilla en la Alta y Plena Edad Media.

3 fbanos@fyl.uva.es / ORCID iD: https://orcid.org/0000-0002-5352-2027

4 estrella@fyl.uva.es / ORCID iD: https://orcid.org/0000-0001-7981-5859
} 
La Catedral vieja de Salamanca reúne una rica colección de sepulcros medievales entre los que destacan especialmente los sepulcros episcopales, repartidos por distintos lugares del templo. En los numerosos estudios que se les han dedicado ${ }^{3}$ no suele prestarse demasiada atención al sepulcro del obispo don Pedro Pérez ( $+c a .1264$ ), que se encuentra en la capilla de San Martín, esto es, en la capilla alojada en el cuerpo bajo de la torre de las campanas, que es la torre septentrional de la fachada occidental del edificio. Su relativa marginación responde, a buen seguro, al aspecto descarnado con que se nos muestra en la actualidad (Fig. 1). En efecto, se presenta como un arcosolio desnudo, desprovisto de cualquier vestigio de decoración escultórica o pictórica, que se abre en el muro meridional de la capilla, guardando una prudente distancia de respeto con respecto al área del altar, que se disponía en el muro oriental de este espacio. Su ubicación vino propiciada por la singular disposición arquitectónica de la capilla de San Martín (Fig. 2), constituida por dos ambientes paralelos a modo de naves que son consecuencia de la integración en su interior del contrafuerte occidental del ángulo noroccidental del edificio: ${ }^{4}$ se configuraron así una "nave meridional», con funciones de acceso y de panteón, y una «nave septentrional», con funciones propiamente litúrgicas, si bien con el correr del tiempo esta acabaría siendo colonizada, así mismo, por sepulcros.

\section{FIGURA 1}

Sepulcro del obispo Pedro Pérez en la capilla de San Martín de la Catedral vieja de Salamanca

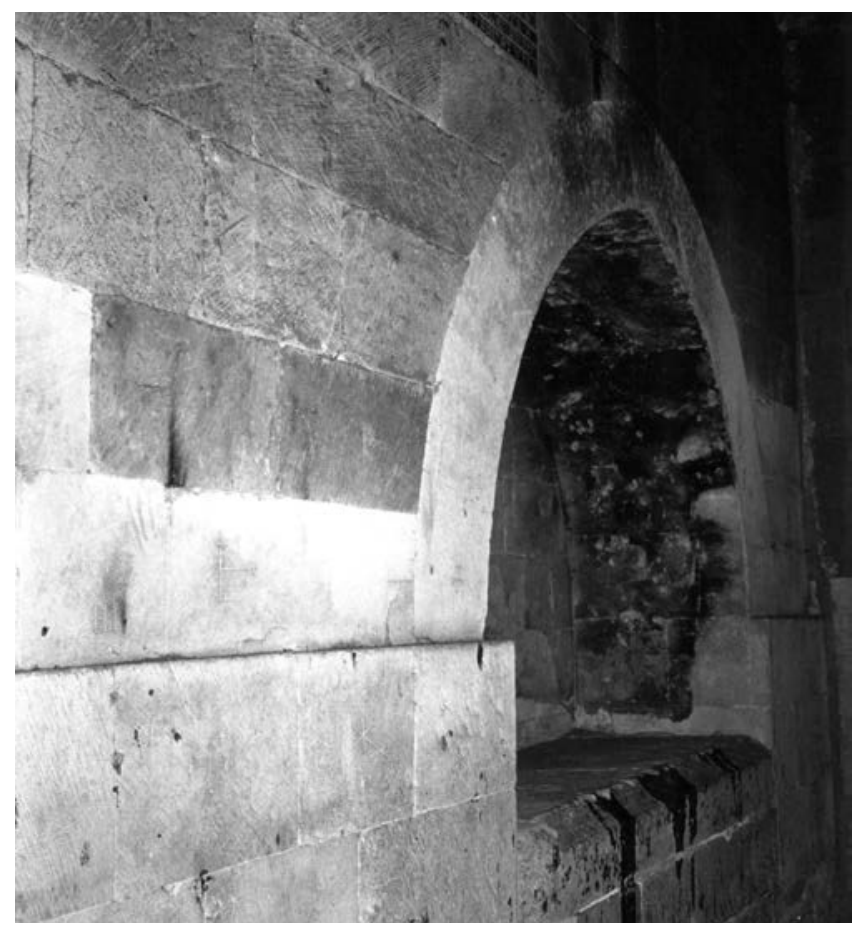

3 El estudio clásico de referencia se debe a Gómez-Moreno (1967: 1, 117-125; 2, láms. 52-70). Estudios recientes se deben a Ruiz Maldonado (2012: 189-254) y a Lahoz (2014: 233-313), quienes, además, han dedicado importantes monografías a varios de los sepulcros medievales catedralicios.

4 No compartimos, por tanto, la interpretación que hace de este espacio Lahoz (2014: 272), que piensa que el muro que separa los dos ambientes paralelos es un "muro de refuerzo» fabricado a posteriori que alteró la espacialidad original de la capilla.
La adscripción de este monumento, aparentemente senciIlo, al obispo Pedro Pérez está asegurada por el epitafio inciso y polícromo que se dispone por encima y a la izquierda del mismo (Fig. 3), y por el libro de aniversarios de la Catedral, compilado originalmente a principios del siglo XVI, acaso en relación con el proyecto de construcción de una nueva Catedral que había de trastocar necesariamente todas las ceremonias que se venían celebrando en su interior. ${ }^{5}$ El primero dice así: ${ }^{6}$

+ HIC PRESVL PETRUS PETRI IACET ALMA MARIA / EIUS SIS ANIME DUX VIA VIRGO PIA / EGREGIUS SOCIUS HVMILIS PIUS ATQUE BENIGNUS / VIR FVIT ET PACIENS PRELATI NOMINE DIGNUS / OMNIBUS HOSPICIVM FVIT HIC GAVDENS DARE DONVM / CLERI PRESIDIVM PROMTUS AD OMNE BONVM / HIC EXPENDEBAT DANS CVNTIS QUICQUID HABEBAT / HIC DARE NON RENVIT MENS DARE TOTA FVIT / PRESVLE DE PETRO BREVITER VOLO DICERE METRO / QVEM TEGIT HEC PETRA PER MEA SCRIBO METRA / MORS FVIT IPSIUS MVLTIS LACRIMABILE FVNUS / HVIC MISERERE DEVS QUI REGNAS TRINUS ET VNUS.

El segundo señala lo siguiente para el 30 de abril: «Por don Pero Pérez, obispo de Salamanca, que yaze en la capilla de sant Martín en vn arco afigurado, se haze aniversario este día y es la missa del altar mayor ${ }^{7}{ }^{7}$

En el libro de aniversarios el sepulcro de Pedro Pérez se describe como "vn arco afigurado», expresión empleada en

\section{FIGURA 2}

Planta de la capilla de San Martín de la Catedral vieja de Salamanca: A.- acceso desde la nave del Evangelio de la iglesia; B.- sepulcro del obispo Pedro Pérez (muro meridional); C.- altar (muro oriental), decorado con pinturas murales

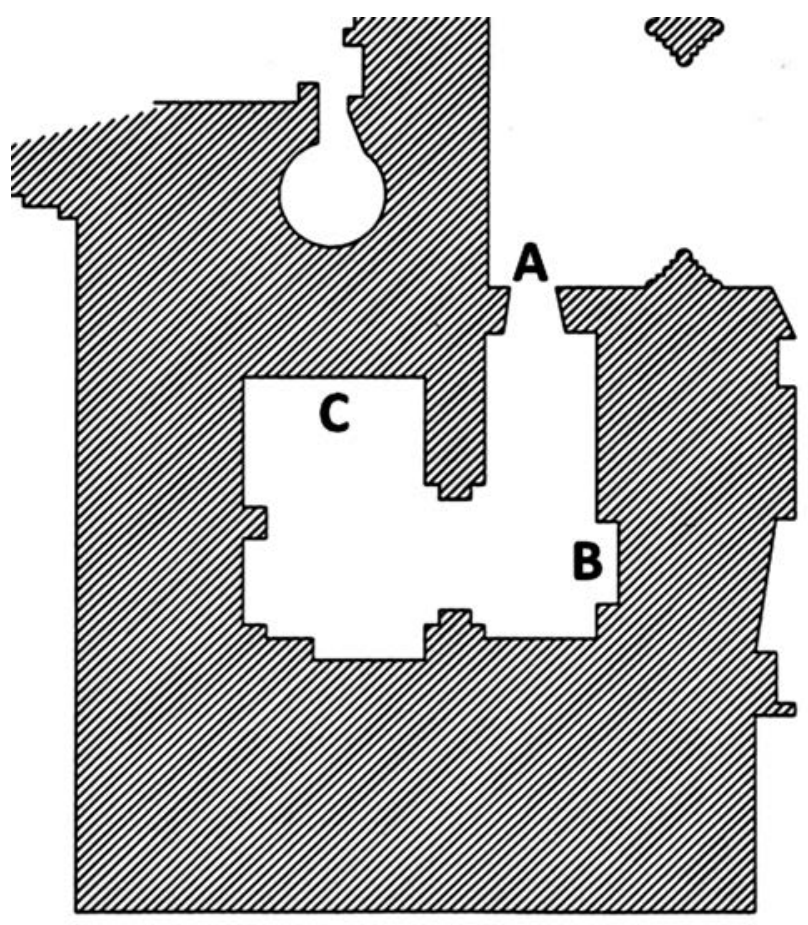

Sobre este complejo documento, v. Azpeitia Martín 2007: 107-145.

Indicamos en cursiva el desarrollo de las abreviaturas.

Archivo de la Catedral de Salamanca, Caj. 67, leg. 3, núm. 1, ff. $87 r-87 v$. 
FIgURA 3

Epitafio del obispo Pedro Pérez en la capilla de San Martín de la Catedral vieja de Salamanca

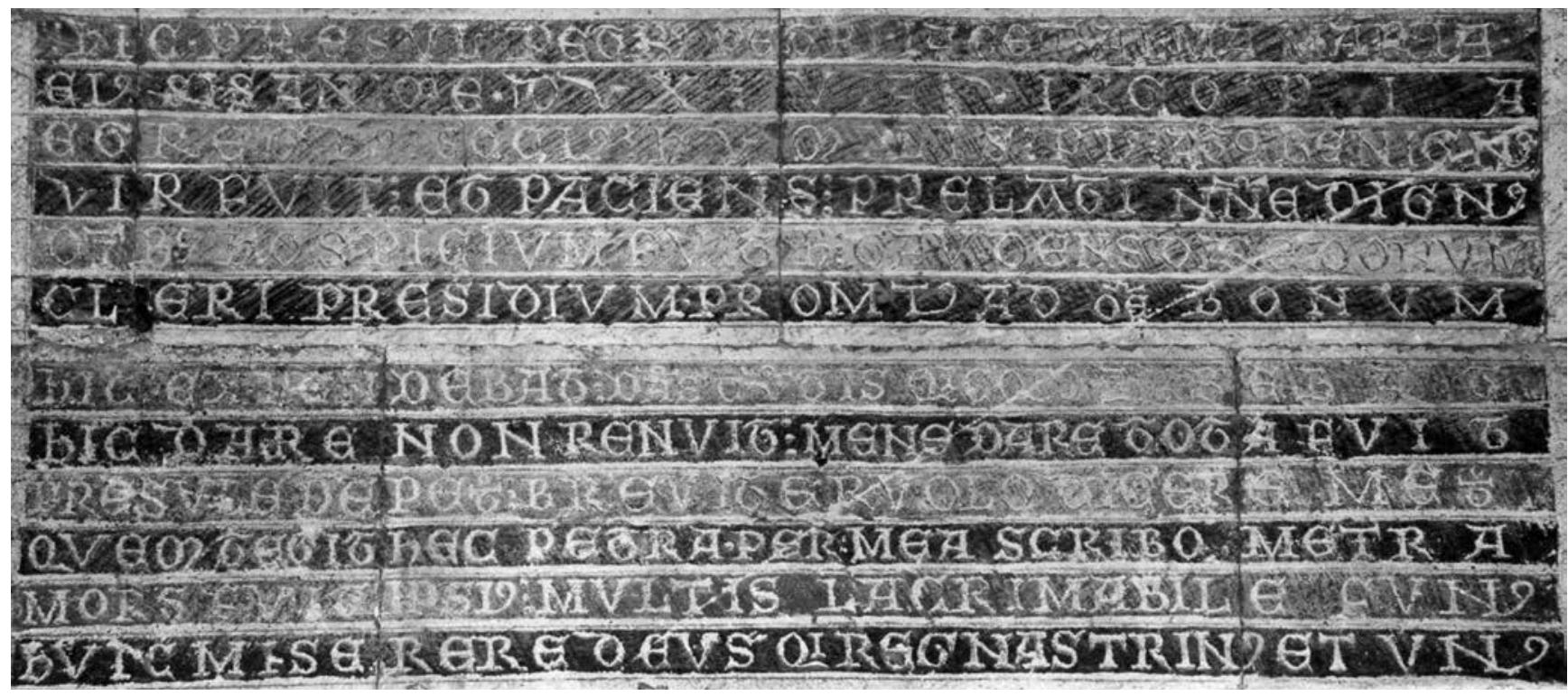

otras ocasiones en este documento para referirse a aquellos sepulcros monumentales que incorporan escultura y/o pintura, lo cual nos pone ante la evidencia de que el sepulcro de Pedro Pérez no fue siempre el descarnado arcosolio que nos es dado contemplar en la actualidad. Fue el paulatino abandono de la capilla de San Martín como espacio litúrgico y funerario, consumado cuando, a partir del siglo XVI, la construcción de la Catedral nueva convirtió este espacio en un cuarto oscuro, ${ }^{8}$ el que redujo el sepulcro de Pedro Pérez a una ruina apenas digna de atención, que no se pudo recuperar cuando se restauró la capilla de San Martín con fines museísticos a mediados del siglo XX. ${ }^{9}$

$Y$, sin embargo, el sepulcro de Pedro Pérez reúne suficientes elementos de interés como para que nos ocupemos de él. No nos referimos tanto a su decoración escultórica y/o pictórica, que por desgracia nunca nos será dado conocer y que acaso proporcionó un modelo para los sepulcros salmantinos, bien caracterizados, que se fabricaron a lo largo de las décadas posteriores, ${ }^{10}$ como al hecho siguiente: el sepulcro del obispo Pedro Pérez es el más antiguo de los sepulcros conservados o documentados (sea por epitafios sea por documentos escritos de naturaleza diversa) no solo del interior de la capilla de San Martín, sino del interior de la Catedral vieja de Salamanca en su conjunto, aunque es cierto que se halla en un espacio periférico e incluso marginal, pero acorde con la paulatina conquista de los interiores de los templos como espacios funerarios que se venía verificando desde el siglo XII. ${ }^{11}$ La propia advocación de la capi-

8 Cuarto destinado finalmente al almacenamiento del aceite que se empleaba en las lámparas de la Catedral: de ahí el nombre de capilla del aceite por el que también se le ha conocido en la historiografía.

9 Sobre la restauración de la capilla de San Martín en 1950-1951, v. Jiménez García 2014: 1770-1774.

10 Gutiérrez Baños 2007: 203-204.

11 Bango Torviso 1992: 110-114 y 123-124. A finales del siglo XII la Catedral vieja de Salamanca se había dotado de un claustro concebido fundamentalmente con una finalidad cementerial (Carrero Santamaría 2005: 17-44). Sobre la capilla de San Martín como espacio funerario, v. Gutiérrez Baños 2011: 45-56; Lahoz 2014: 262-279.

\section{FIGURA 4}

Pinturas murales del muro oriental de la capilla de San Martín de la Catedral vieja de Salamanca, firmadas y fechadas por Antón Sánchez de Segovia en 1262

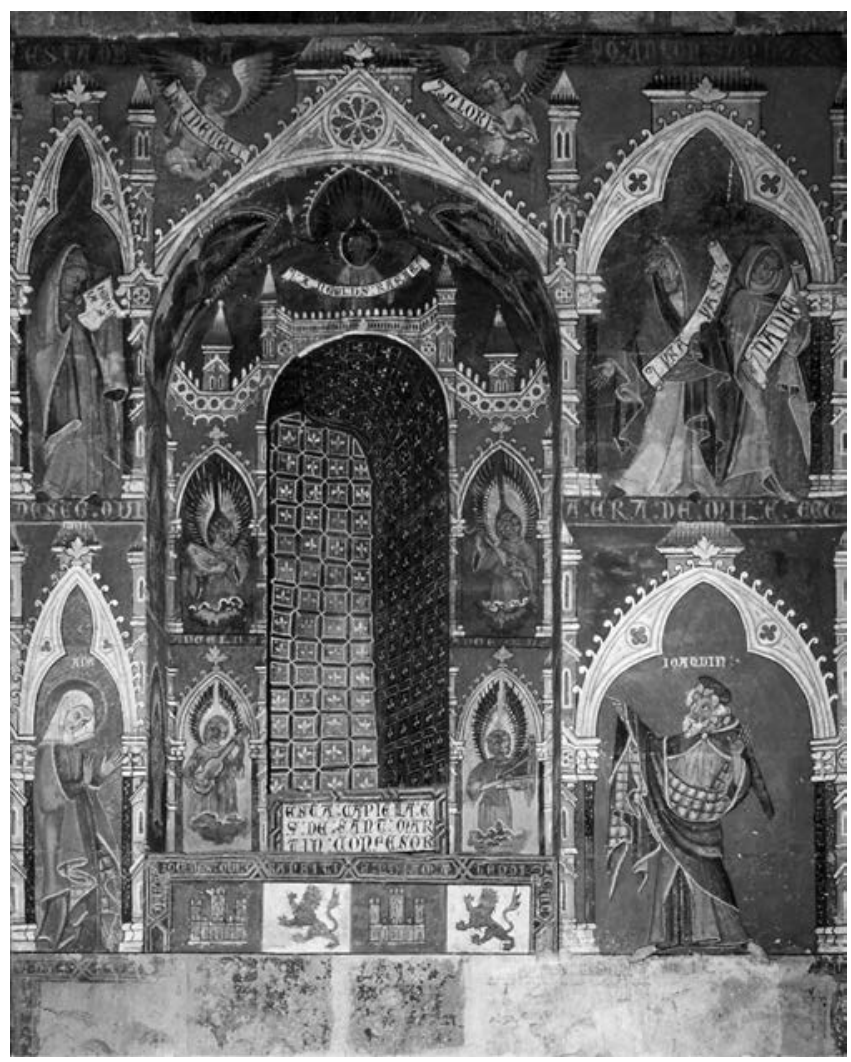

Ila, que apela al carácter salvífico de la virtud de la caridad, incide en el carácter funerario de este espacio. ${ }^{12}$ Además se sucedieron en ella distintos enterramientos hasta mediados del siglo XIV, destacando entre ellos los de otros dos obispos

\footnotetext{
12 Sánchez Ameijeiras 1993: 234-240.
} 
de Salamanca. ${ }^{13}$ Las pinturas murales que decoraban su altar ostentan la fecha de 1262, perteneciente al episcopado de Pedro Pérez y próxima a su fallecimiento ca. 1264, abonando la idea de que pudo ser este prelado el que habilitara ese ámbito como espacio funerario bajo la advocación de San Martín (algo que, por desgracia, no pasa de ser una hipótesis, razonada y razonable, que como tal asumimos, si bien carece de respaldo documental). Estas pinturas murales, que estuvieron presididas por una imagen de bulto de la Virgen con el Niño, son excepcionales desde todos los puntos de vista (Fig. 4). ${ }^{14}$ Lo son, en primer lugar, por su disposición, que, aunque orientada principalmente a resolver de manera eficaz los condicionantes impuestos por la fábrica románica del muro que les sirve de soporte, se inspira, entre otras fuentes, en

\section{FIGURA 5}

Sello y contrasello del obispo Pedro Pérez (impronta de 1259), Archivo de la Catedral de Salamanca, Caj. 13, leg. 1, núm. 4. (C) Archivo de la Catedral de Salamanca

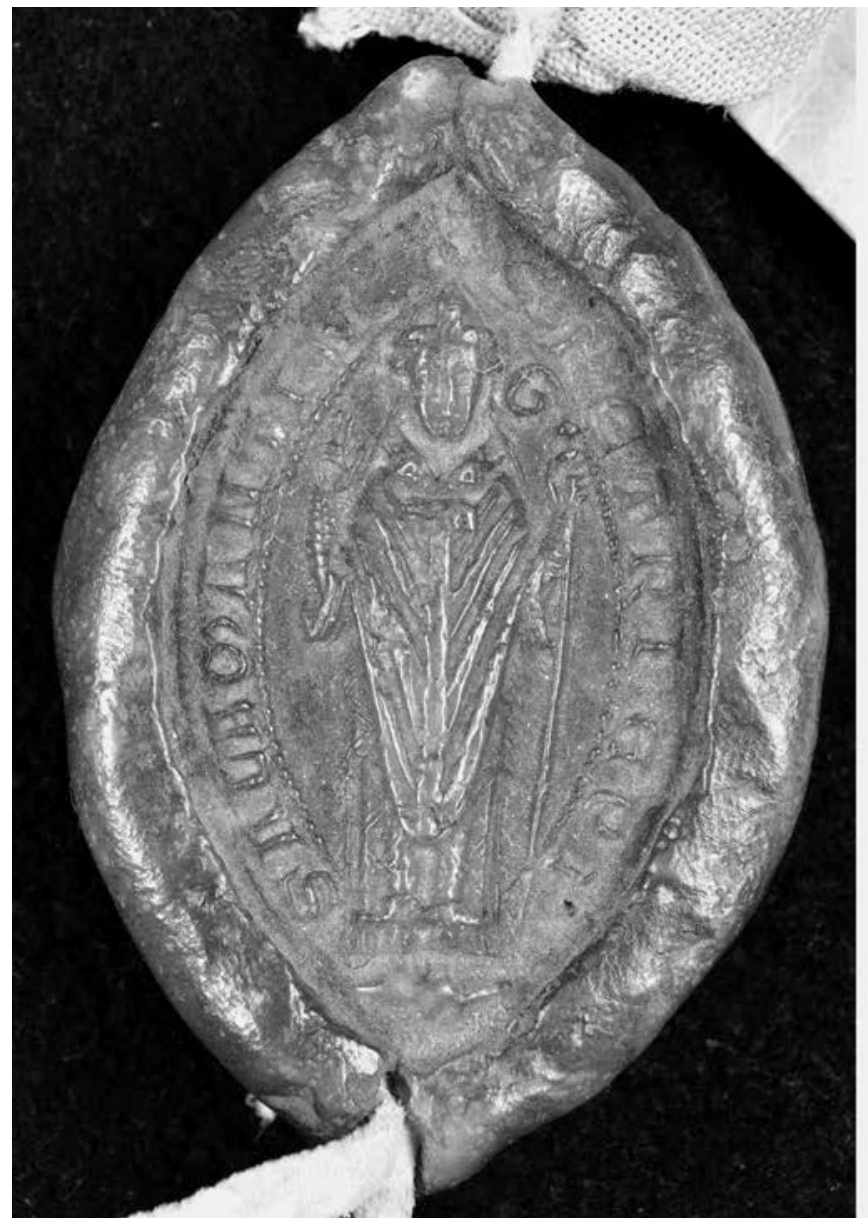

13 El libro de aniversarios reseña los enterramientos de Pedro Pérez († ca. 1264; v. supra n. 7) y de Rodrigo Díaz († 1339; v. Archivo de la Catedral de Salamanca, Caj. 67, leg. 3, núm. 1, f. 101v). Además, en su testamento de 20 de septiembre de 1300 Martín Pérez, que era abad de San Marcelo y canónigo de la iglesia de León y compañero de la iglesia de Salamanca, pide ser enterrado «enna capilla de San Martino, a los pies del obispo don Pedro y de don Gonçalo, çerca mío hermano Arias Pérez» (Guadalupe Beraza et alii 2009: 684), siendo probablemente «don Gonçalo» el obispo de Salamanca Gonzalo Rodríguez ( ${ }^{\dagger}$ a. de 1278; v. Beltrán de Heredia 1970-1972: 1, 79). Gómez-Moreno (1967: 1, 125) señala además que el sepulcro del obispo Gonzalo de Vivero († 1480), que en la actualidad se encuentra en la capilla mayor, "primero estuvo en la capilla de San Martín», si bien existen noticias ciertas acerca de su enterramiento en su lugar actual desde principios del siglo XVI, proporcionadas, por ejemplo, por el libro de aniversarios (Azpeitia Martín 2007: 142, n.o 10). Sobre las vicisitudes de su enterramiento, v. Cosmen Alonso 2018: 47-49. Cierto Gómez Fernández ( 1317), a quien se cita en ocasiones como sepultado en la capilla de San Martín, estuvo enterrado en realidad en las inmediaciones de este espacio: "cabe la capilla de sant Martín» (Archivo de la Catedral de Salamanca, Caj. 67, leg. 3, núm. 1, f. 21r).

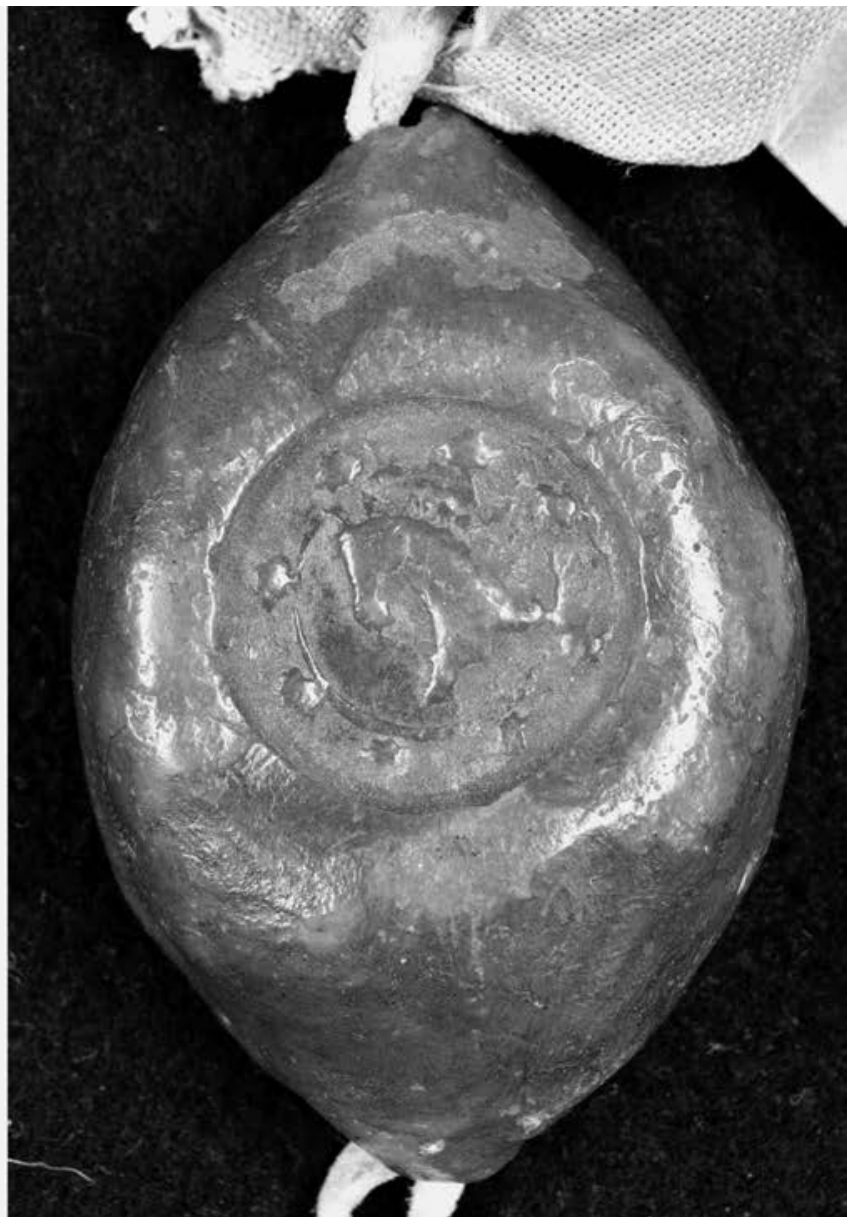

un modelo de decoración de altar bastante ajeno a los usos castellanos consistente en un retablo de formato rectangular apaisado sobre el que se dispone una imagen de culto: la anteriormente mencionada imagen de bulto de la Virgen con el Niño, que no se conserva. Lo son, en segundo lugar, por su estilo, sin precedentes en Castilla y deudor del desarrollado en las cortes de París y de Londres en las décadas de 1240 y de 1250. Lo son, finalmente, por su iconografía, que, más allá de reunir profetas y santos alrededor de la mencionada imagen, dispuesta sobre una compleja representación de la Crucifixión apenas reconocible en la actualidad, incidía en la necesidad, singularidad y excepcionalidad de María en la

14 Sobre estas pinturas murales, v. Gutiérrez Baños 2005a: 2, 143 153, o los estudios más recientes de Ruiz Maldonado (2012: 232-237) y de Lahoz (2014: 266-272). Específicamente sobre sus aspectos estilísticos, v. Gutiérrez Baños 2005b: 13-63, y sobre sus aspectos iconográficos, v. Gutiérrez Baños 2018: 66-81. 
obra de la Redención de acuerdo con controversias teológicas que estaban muy vivas en el siglo XIII.

¿Quién fue este Pedro Pérez capaz, según parece, de poner en marcha un conjunto tan absolutamente excepcional e innovador como la capilla de San Martín de la Catedral vieja de Salamanca? Su sello como obispo de Salamanca, del que se conservan varias improntas del periodo 1253-1260, no nos proporciona sino una imagen ideal del personaje (Fig. 5$)^{15}$ y, si acudimos a su epitafio en busca de respuestas más sustanciosas, nos encontramos únicamente con un meritorio ejercicio literario que no nos aporta datos ciertos sobre su biografía, ${ }^{16}$ aun cuando por sus características sea indicativo del ambiente intelectual en que discurrió su vida. Este epitafio es un signo más de la singularidad del personaje, cuyas circunstancias vitales, no obstante, parecen estar claras para la historiografía. Una síntesis reciente y absolutamente competente lo presentaba en los siguientes términos: "Sustituirá al obispo Martín, en 1246, Pedro Pérez (1246-1264), canónigo y dignidad de arcediano en la Catedral de Salamanca. Cancelario de Alfonso IX, acompañó a su hijo Fernando III en las campañas militares. Con fama de hombre virtuoso y generoso con los pobres, consiguió muchos bienes y privilegios para Salamanca y su catedral (...) El último acto del ilustre obispo Pedro Pérez en su relación con el Cabildo salmantino, será la fundación de la Capilla de San Martín o Capilla del aceite $» .{ }^{17}$ Sin embargo, muchas de estas afirmaciones se retrotraen a fuentes historiográficas antiguas que es necesario revisar.

En este artículo estudiaremos, en primer lugar, el epitafio del obispo Pedro Pérez, testimonio interesante de la poesía latina producida en la Corona de Castilla en el siglo XIII, y abordaremos a continuación cómo ha ido configurándose su biografía para intentar superar los vicios que han ido enquistándose en ella y, sobre todo, para determinar quién fue realmente este personaje, labor en absoluto sencilla, pues a nadie se le oculta que la vulgaridad de su nombre dificulta la tarea: se cuentan por cientos, si no por miles, los individuos llamados Pedro Pérez que pueden aparecer en la documentación del siglo XIII.

\section{El epitafio de Pedro Pérez: edición, tRAducción y ESTUdio}

Es este epitafio un poema compuesto por una docena de versos cuantitativos, como el propio texto advierte (metro v. 9; per mea metra v. 10). La copia epigráfica hace coincidir cada verso con una línea, los impares escritos sobre franjas rojas y los pares sobre negras, y deja sin escribir una franja a mitad del poema, entre el sexto y el séptimo verso, que lo divide en dos partes iguales y salva la junta de dos hiladas de

15 Muestra la efigie de pie del prelado bendiciendo con la mano derecha y sosteniendo el báculo con la mano izquierda rodeada por la inscripción SIGILLVM PETRI EPISCOPI SALAMANTINI. Gómez-Moreno (1967: 1, 158) describe así su contrasello: «Por detrás, impreso un escudito redondo, con cabeza de caballo embridado y ocho veneras en la orla». No nos atrevemos a pronunciarnos sobre el carácter heráldico efectivo de estas señales, que, en cualquier caso, no hemos podido vincular con linaje alguno.

16 Por no proporcionar, no proporciona ni siquiera la fecha de su fallecimiento, lo que nos induce a pensar que pudo ser compuesto y labrado en vida del propio prelado.

17 leronimus... 2002: 253-255. sillares, lo que hace patente la cuidadosa planificación de la disposición del texto en la pared.

El epitafio ha recibido hasta el momento presente las siguientes once ediciones: González Dávila 1606: 239-240; González Dávila 1618: 86; Masdeu 1791: 277-278; Dorado 1776: 218; Quadrado 1865: 35, n. 1 (1884: 51, n. 2); Araújo 1884: 2, 24; Villar y Macías 1887: 1, 140; Portal Monge 1988: 25-27; Fernández Vallina 1999b: 268-269; Lahoz 2014: 264265; Rodríguez Suárez 2017: 98. Gómez-Moreno (1967: 1, 155) remite a la edición de Quadrado. Estas son sus características:

Con el mérito de ser pioneras, las dos ediciones publicadas por González Dávila omiten el tercer verso y en el v. 12 escriben hunc en lugar del huic original. Siguen su texto, incluyendo la omisión y el error, Masdeu en 1791, quien además escribe maltis en lugar de multis (v. 11), y Dorado, quien corrige el hunc en huius y añade nuevos errores: omne en lugar de donum (v. 5), sic en lugar de hic (v. 7), la omisión de fuit (v. 11) y de qui regnas (v. 12), y la adición de et ante uia (v. 2). Quadrado hace su edición de forma independiente a partir de la inscripción original, que también describe en detalle, por ello ofrece el texto ya completo, aunque con un error de lectura: et por hic (v. 5), al que, en la edición de su obra de 1884, se une una mera errata: pea por per (v. 10). Son deudoras del texto de Quadrado de 1865 las ediciones de Araújo, Villar y Macías, Portal Monge y Fernández Vallina, aunque este último añade in ante uia (v. 2). ${ }^{18}$ Finalmente, el texto de Lahoz reproduce, según afirma la autora, el de Fernández Vallina; ${ }^{19}$ y el de Rodríguez Suárez es resultado de su propia lectura de la inscripción y está libre de errores. Nuestra edición se basa igualmente en la lectura personal del original y no va acompañada de aparato crítico porque nada resulta digno de reseñarse en él dado que, por un lado, no hay ningún lugar problemático en el texto $y$, por otro, como acabamos de señalar, las divergencias de los editores anteriores son producto de errores y, en consecuencia, no tiene sentido recogerlas.

Casi todos los editores, incluyendo los más recientes, han puntuado el texto del epitafio por lo general de forma poco ajustada a las construcciones y al sentido del mismo. Respecto a la grafía adoptada, González Dávila y sus seguidores, como era habitual en la época, no reproducen la del original, sino que han reconstruido la ortografía del latín clásico, con alguna pequeña divergencia entre ellos; Quadrado y sus seguidores mantienen unas veces la grafía original, pero otras restituyen la clásica: por ejemplo, animae (v. 2), patiens (v. 4), hospitium (v. 5), promptus (v. 6), lacrymabile (v. 11), si bien Fernández Vallina nunca escribe el diptongo ae. Por último, Rodríguez Suárez es la única que respeta a lo largo de toda la inscripción la forma gráfica original, salvo en lo que respecta a $u / v$, que en la piedra se escribe siempre $v$, mientras ella utiliza $u$ para la semivocal y $v$ para la semiconsonante. Nosotros procedemos a este respecto como suele ser habitual en las ediciones modernas de textos latinos medievales: respetamos al máximo la grafía original, para dejar testimonio de las costumbres gráficas medievales, muy diferentes de las antiguas, salvo en el caso de $u / v$, grafías indistintas en la Edad Media, que nosotros escribimos

18 Pero sigue leyendo et gaudens (v. 5) como el resto.

19 Si bien en la grafía lacrymabile (v. 11) y en la coma que sitúa entre miserere y Deus (v. 12) coincide con el texto de Quadrado. 
siempre con $u$ en minúscula y con $V$ en mayúscula; resolvemos las abreviaturas sin indicarlo, pues se pueden ver en la edición epigráfica incluida al comienzo de este trabajo; añadimos puntuación moderna al texto y adecuada a su sentido, y, por supuesto, escribimos un verso por línea.

Respecto a la traducción del titulus, tan solo Masdeu (1791: 278) y Rodríguez Suárez (2017: 98) ofrecen una completa, aunque con ciertas deficiencias, y Fernández Vallina (1999a: 32) traduce un fragmento. La nuestra se ha realizado en formato de versículo libre, haciendo que el contenido de cada uno se ajuste estrictamente al del verso latino correspondiente. Intentamos reproducir lo más fielmente posible el sentido, estructura, figuras y rima del original, aunque sin sacrificar nunca el sentido ni la corrección del castellano.

A continuación editamos los versos latinos enfrentados a su esquema métrico: ${ }^{20}$

Hic presul Petrus Petri iacet. Alma Maria, eius sis anime dux, uia, Virgo pia.

Egregius socius; humilis, pius atque benignus uir fuit et paciens, prelati nomine dignus.

5 Omnibus hospicium fuit hic gaudens dare donum, cleri presidium promtus ad omne bonum.

Hic expendebat dans cunctis quicquid habebat. Hic dare non renuit, mens dare tota fuit.

Presule de Petro breuiter uolo dicere metro, quem tegit hec petra per mea scribo metra.

Mors fuit ipsius multis lacrimabile funus.

Huic miserere, Deus, qui regnas trinus et unus.

Aquí yace el prelado Pedro Pérez. Excelsa María, sé de su alma guía y senda, Virgen pía.

Colega distinguido; humilde, pío y benigno

varón fue y paciente, del título de prelado digno.

5 A todos hospitalidad ofrecía y dádivas daba con alegría, al clero amparo, pues a la bondad estaba inclinado.

Con liberalidad obraba y a todos lo que tenía daba. No declinó regalar, no tenía más deseo que dar.

Del prelado Pedro con brevedad quiero en verso hablar, al que cubre esta piedra mis versos dedicar.

Su muerte fue para gentes incontables una deplorable pérdida.

Compadécete de él, Dios mío, tú que uno y trino reinas. como este, el poeta ha decidido no extenderlos a toda su composición. Sin embargo, domina la técnica métrica y es capaz de construir versos artificiales y exigentes, como son los cuantitativos, con una factura perfecta.

Lo más reseñable en la prosodia de estos versos es que no se observa ningún error. Todo se halla dentro de las costumbres en uso en la Edad Media, como que el genitivo ipsius (v. 11) tenga su segunda $i$ larga y situada en tiempo débil, que la sílaba inicial de eius (v. 2) sea larga, que el dativo huic (v. 12) se mida como monosílabo largo ${ }^{21}$ o la medida larga tanto del adverbio (v. 1) como del pronombre hic (v. 7). ${ }^{22} \mathrm{Al}$ arbitrio del poeta quedaba la medida de las sílabas situadas ante el grupo consonántico muta cum liquida, y aquí se considera siempre larga la del nombre propio del difunto: Pētrus (vv. 1 y 9) y el sustantivo con él relacionado: pētra (v. 10), aunque no otras como, por ejemplo, lăcrimabile (v. 11). 
Marīa (v. 1), muy normalmente aplicada en la Edad Media a los nombres propios de ese origen.

En lo que se refiere a la formación de los dos tipos de versos empleados conviene destacar varias cosas. En primer lugar, mantiene la costumbre antigua del predominio del comienzo dactílico, pie de ritmo vivo que además domina el conjunto de sus versos al estilo ovidiano, ${ }^{24} y$ sigue a rajatabla la norma de que el quinto pie del hexámetro y los dos últimos del pentámetro deben ser dáctilos (-uu). En el esquema del resto de los pies el poeta busca la variedad y la consigue enormemente, pues en el hexámetro solo se repite el esquema $D^{2} E^{25}$ en los vv. 4 y 12 , y ED en el pentámetro, en los vv. 2 y 6 , que es la estructura menos empleada por los poetas antiguos y los medievales clasicistas; los demás pies son todos diferentes: 10: EEED, 3ㅇ: DDDD, 5ㅇ: DDDE, 7ㅇ: EEEE, 9ㅇ: DEDD, 11ㅇ: DEED en los hexámetros; 8 ㅇ DD y 10 으 De en los pentámetros. La variedad también se ha extendido a la relación entre los dos pies iniciales del pentámetro y su correspondiente hexámetro, pues solo en una ocasión se repite en aquel el esquema inicial de este (DE en los vv. 9 y 10). Como era habitual desde antiguo, la unidad de sentido se mantiene en todos los dísticos; en particular en los dos últimos (vv. 7-8 y 9-10) el pentámetro repite, variando la expresión, la misma idea manifestada en el hexámetro.

Respecto a la cesura del hexámetro parece haberse convertido en obligatoria la pentemímeres (tras el quinto medio pie), pues está presente en todos los versos. ${ }^{26} \mathrm{~A}$ ella se unen la trihemímeres (tras el tercero), la heptamímeres (tras el séptimo) y la diéresis bucólica ${ }^{27}$ en los vv. 1, 3 y 9; la heptemímeres y la diéresis bucólica en el v. 4; solo la heptemímeres en los vv. 5 y 11, y únicamente la diéresis bucólica en los vv. 7 y 12. En el v. 5 coincide un final de palabra tras el quinto longum, algo propio de la tendencia métrica medievalizante. ${ }^{28}$

La cláusula o dos pies finales del hexámetro es una de las partes más cuidadas del verso. Desde la Antigüedad la palabra final era preferentemente de dos o tres sílabas, que son las únicas que se encuentran en este poema, con predominio claro de los bisílabos, que terminan cinco versos $(4,5$, 9, 11 y 12), en la línea del hexámetro heroico. Las dos palabras que forman la cláusula son también mayoritariamente de este tipo: los vv. 1, 3 y 7 tienen el tipo conde sepulcro, es decir, 2+3; y los vv. 4, 9 y 11 el inverso, 3+2. De los dos restantes uno (v. 12) es del tipo gente tot annos, considerado también normal entre los clásicos, pero el esquema si bona norint del v. 5 apenas está presente en aquellos o en las obras medievales clasicistas, y aquí además no tiene el

2422 dáctilos (-uu) frente a 18 espondeos (--). En seguir la línea de Ovidio y no la de Virgilio en este aspecto también coincide con la mencionada Vita Didaci, v. Pérez Rodríguez 2008: 110.

$25 \mathrm{D}=$ dáctilo (-uu), $\mathrm{E}=$ espondeo (--).

26 En esto no coincide con la Vita Didaci, pero sí, por ejemplo, con Alcuino, v. Pérez Rodríguez 2008: 115

27 Se llama así a la coincidencia entre el final de palabra y el final del cuarto pie del hexámetro.

28 Supone un porcentaje del $12,5 \%$, que lo acerca a las composiciones medievales de tendencia no clásica como las de Hugo Primas (16,6 \%) o la comedia Asinarius (10 \%) del siglo XII; la Vita Didaci, en cambio, es más moderada en su uso, con un 6,33 \%, v. Pérez Rodríguez 2008: 113-115, aunque es posible que los pocos versos de este epitafio puedan distorsionar los datos. monosílabo inicial que colocaban los clásicos las pocas veces que lo empleaban. Sin embargo, todos los pentámetros acaban a la forma clásica con un bisílabo, sin que preocupe la monotonía del poema por el predominio total de los finales de dos sílabas. Sigue la línea clásica al hacer coincidir el acento de palabra y el tiempo fuerte en el último pie de todos los hexámetros, mientras que en el quinto pie hay una excepción (gau/dēns dáre / dónum v. 5).

En resumen, estos versos pueden ser calificados de «medievales» por la total ausencia de elisiones, por la presencia de la cláusula anómala $1+2+2$, del espacio interverbal tras el quinto longum y la no coincidencia de tiempo fuerte e ictus en el quinto pie del hexámetro.

También es claramente medieval la incorporación de la rima a los versos cuantitativos. Esta no se produce de forma totalmente regular, pues a veces tiene lugar a partir de la penúltima vocal, como se había vuelto común desde el siglo XII, pero otras solo a partir de la última. Seis de los hexámetros son leoninos, es decir rima la palabra ante la cesura pentemímeres con la final, solo en dos con rima bisilábica:

\section{v. 3: socius / benignus; v. 5: hospicium / donum; v. 7: expendebat / habebat}

v. 9: Petro / metro; v. 11: ipsius / funus; v. 12: Deus / unus

También son leoninos tres de los pentámetros y en dos de ellos la rima es bisilábica:

\section{v. 6: presidium / bonum; v. 8: renuit / fuit; v. 10: petra / metra}

Pero el juego con la rima en el poema no se limita a los versos apuntados, sino que es bastante más complejo, pues a esas rimas se unen otras que relacionan dos versos. En el dístico elegíaco que abre el poema riman los finales de ambos versos entre sí con rima bisilábica (Maria / pia); el par de hexámetros que lo sigue tiene también rima bisilábica entre sus finales (benignus / dignus), e igualmente el subsiguiente dístico (donum / bonum), pero en él a esa rima final se une otra entre la palabra situada ante la pentemímeres de ambos versos (hospicium / presidium), es decir, son versos uentrini. Una situación semejante se repite en los dos hexámetros que cierran el poema: sus finales riman con rima bisilábica (funus / unus) y también las palabras que preceden a la cesura pentemímeres, aunque en este caso la rima afecta solo al final: (ipsius / Deus). Así siguiendo el proceder más habitual de los poetas medievales, que se recrean en el dominio de la técnica versificadora, también el poeta anónimo que ha compuesto este epitafio se esmera en este aspecto y tiene la suficiente formación como para hacerlo con habilidad y sin incurrir en incorrecciones ni permitirse ninguna licencia impropia.

En el aspecto lingüístico hay que señalar que la grafía empleada en el poema no se aparta de la que era característica de un hombre culto medieval: el diptongo ae monoptongado en $e$ (presul v. 1 , anime v. 2 , etc.), el grupo $t i+$ vocal escrito a veces como ci (paciens v.4, hospicium v. 5) o la reducción de los grupos consonánticos (promtus v. 6), mientras es habitual desde antiguo la asimilación que se ha producido en quicquid (v. 7) y también la grafía lacrimabile. En la sintaxis llama la atención la construcción del verbo 
misereor (v. 12) con dativo (huic) en lugar de con genitivo, pero ese caso se hace habitual con él desde los escritos cristianos del Bajo Imperio.

Desde un punto de vista literario, el autor de este epitafio se revela más como un buen versificador y un excelente conocedor de la poesía funeraria que como un inspirado poeta, puesto que tanto el contenido como la expresión de sus versos son en gran medida convencionales y formularios dentro de la poesía dactílica mortuoria medieval. ${ }^{29}$

Constituyen su contenido algunos de los tópicos característicos de los epitafios, tanto versificados como prosísticos. El primero es la identidad del difunto, para lo que se emplea una de las fórmulas más convencionales desde época romana cuando la inscripción se halla sobre la misma tumba: ${ }^{30}$ el adverbio locativo hic (v. 1) en referencia al lugar físico de sepultura y el verbo iacet, en presente de indicativo; entre ambos se ha colocado el nombre del difunto, al que se identifica con su dignidad (presul) y su nombre y apellido.

Otro elemento habitual es el ruego por la salvación del finado, que aquí se plasma en dos invocaciones situadas al inicio y al final de la pieza. La primera se dirige a la Virgen María, cuya presencia en una inscripción del siglo xIII se explica por la importancia que adquirió su figura y la enorme intensificación que experimentó su culto durante tal siglo. Además, por su condición de ser humano se la consideraba más cercana a los hombres que la divinidad y la Iglesia le adjudicaba el papel de mediadora entre aquellos y esta, que el poema le pide que ejerza con el obispo muerto. Para ello utiliza dos de las designaciones marianas más comunes: es "guía» (dux v. 2) de los hombres hacia el cielo o, lo que es lo mismo, "senda» (uia v. 2) que conduce directamente allí. Igualmente se la califica con dos de los adjetivos que en la Edad Media suelen acompañar su nombre, el de Dios o el de los santos: alma (v. 1) y pia (v. 2). Ambos son términos del latín clásico, pero alma ya no conserva en este contexto su significado antiguo de «nutricio, que alimenta, vivificante, revitalizador», sino que se ha convertido en un calificativo de reverencia para los seres divinos o cercanos a la divinidad, que se podría traducir como «excelso, divino, venerable, sublime, santo ${ }^{31}$ En esta invocación mariana se menciona expresamente el alma del difunto (anime v. 2), de la que se hará cargo la Virgen, y así también se expresa la antítesis, habitual en los epitafios cristianos, entre la situación del cuerpo, que se queda en la tierra (hic iacet v. 1), y la del alma, cuya vocación es el cielo. ${ }^{32}$ El segundo apóstrofe cierra el epitafio y va dirigido a Dios. Se expresa con la fórmula miserere Deus, procedente de los salmos $(55,56)$ y usada en las preces mozárabes, muy difundidas incluso fuera de España, a la que se ha añadido una oración de relativo trinitaria, que se emplea con frecuencia en las vidas de santos y otros poemas métricos siempre como segundo hemistiquio del hexámetro, al igual que aquí.

29 Este proceder es habitual en las inscripciones métricas medievales, incluso se observa en ellas el recurso a formularios, v. Favreau 1979: 34-44.

30 Muñoz García de Iturrospe 1995: 185.

31 V. MLW, s. v.

32 Muñoz García de Iturrospe 1995: 185-186; Fernández Martínez 2012: 38.
Puesto que la poesía funeraria pretende preservar el recuerdo del difunto en la memoria de los vivos, uno de sus elementos fundamentales, especialmente desde época cristiana, ${ }^{33}$ es la laudatio, a la que están dedicados aquí seis versos (vv. 3-8). En ella se ponen de relieve las virtutes del prelado, que además lo consagran como modelo para sus congéneres. Tal alabanza podía adoptar distintas formas, pero aquí tenemos representadas dos comunes. En primer lugar, se realiza a través de una enumeración de adjetivos, ${ }^{34}$ seis en este caso (vv. 3-4). Cinco de ellos acompañan al sustantivo uir (v. 4), que era comúnmente empleado en la hagiografía como designación del hombre santo, siendo también tales adjetivos, correspondientes a algunas de las virtudes cristianas más destacadas (humildad, piedad, paciencia y bondad), calificativos habituales de dicha figura. De esta manera, con un vocabulario característico de la literatura hagiográfica se está poniendo al obispo salmantino, aunque sea de forma implícita, a la altura de los santos. El sexto adjetivo (egregius v. 3), también usual en los carmina latina epigráficos, acompaña al sustantivo socius, que, en cambio, apunta hacia un ámbito más humano y específico: los compañeros o colegas de Pedro Pérez, sobre los que se destaca al prelado. Finalmente, en el último adjetivo de la enumeración (dignus v. 4) se introduce una variación estructural, al ser el único acompañado de un determinante en ablativo (prelati nomine v. 4), en el que, además, se incluye un juego de palabras que comentaremos más adelante.

En segundo lugar, el elogio se hace también mediante la descripción del comportamiento en vida del difunto, que se desarrolla en los dos dísticos siguientes (vv. 5-8). El inicial (vv. 5-6) señala la hospitalidad y protección que ofrece el obispo mediante los correspondientes sustantivos (hospicium, presidium) repartidos entre los dos versos, el primero de los cuales se relaciona con un ámbito general a través del dativo omnibus (v. 5) y el segundo con uno particular, su grupo social, a través del genitivo cleri (v. 6), al igual que se hacía en el dístico anterior mediante uir y socius. A esos dos atributos, que ocupan el primer hemistiquio de su respectivo verso, se añaden otros dos en la segunda mitad de tales versos: la generosidad (v. 5) y la bondad (v. 6). La generosidad es una cualidad también omnipresente en las alabanzas cristianas y resulta ampliamente tratada aquí, pues vuelve a ser el tema del último dístico de la laudatio (vv. 7-8), cuyos dos versos repiten la idea de la extrema liberalidad del obispo dando lugar a una amplificatio muy característica de la poesía tardo-medieval: el hexámetro recoge el tópico hagiográfico de que el hombre santo da todo lo que tiene, que introdujo en el repertorio literario cristiano la biografía de Martín de Tours escrita por Sulpicio Severo poco antes de la muerte de aquel en el año 397; el pentámetro convierte esa virtud en la máxima preocupación del difunto, y ambos versos la expresan con la reiteración del verbo do, dare, ya presente en el v. 5. Y todo ello está muy en consonancia con la advocación de la capilla al mencionado santo.

La lamentatio es otro tópico de los tituli fúnebres que aparece aquí, aunque de forma muy breve, pues únicamente el v. 11 alude al dolor que la muerte de Pedro Pérez

33 Cuando ocupa prácticamente todo el texto de las inscripciones, v. Fernández Martínez 2012: 33.

34 Muñoz García de Iturrospe 1995: 266. 
causa, como es normal especificar, a muchos (multis) de los supervivientes, dolor manifestado a través de las lágrimas (lacrimabile).

Hay, sin embargo, un elemento que no es tan habitual en la poesía sobre piedra, aunque sí en la compuesta para pergamino. Se trata de la información sobre la propia obra que se recoge en el siguiente dístico (vv. 9-10): su tema y su forma, que se repiten en ambos versos (presule de Petro / quem tegit hec petra, metro / metra), así como la tópica brevedad (breuiter v. 9). También resulta inaudita en la poesía epigráfica funeraria la aparición del poeta hablando en primera persona sobre su composición, aunque sin desvelar su identidad, y, en cambio, falta un elemento ineludible en este tipo de tituli, la fecha en que tuvo lugar el óbito.

Respecto a las expresiones utilizadas encontramos dos inspiradas en la poesía cristiana tardo-antigua. Promtus ad omne bonum (v. 6) procede de un verso del influyente poeta Venancio Fortunato ( + 610): Cura sacerdotum, promptus ad omne bonum (carm. 2,11,20), también un pentámetro leonino, y ocupa, como en este, el segundo hemistiquio completo. Además, al comienzo de tal línea el epitafio salmantino presenta una construcción idéntica a la del verso fortunatiano, cuyo genitivo se refiere igualmente al estamento sacerdotal (cleri / sacerdotum). No podemos asegurar, sin embargo, que el anónimo poeta la haya tomado directamente de Venancio Fortunato, porque la expresión se utilizó después en un considerable número de poemas, entre ellos diversos tituli métricos. Quem tegit petra (v. 10) se encuentra también en un pentámetro de Venacio Fortunato (carm. 9,2,60), que habla de la sepultura: Nos neque iam repetit quem petra mersa tegit, y pensamos que puede estar inspirada en él porque, si bien el verbo tegit es de muy frecuente uso en las inscripciones funerarias métricas, su sujeto suele ser lapis, no petra. Parece evidente que el poeta salmantino ha elegido petra para establecer un juego de palabras con el nombre del difunto, otro tópico en esta poesía funeraria desde la Antigüedad. ${ }^{35}$ En este caso ambos sustantivos recuerdan la frase de Jesús sobre su Iglesia y el apóstol Pedro (Matth. 116,18). Por otra parte, en el Alexandreis (4, prol. 1), el popular poema épico del vate galo Gualterio de Châtillon (ca. 1200), se emplea la expresión lacrimabile funus en idéntica posición de verso que en este epitafio (v. 11), aunque tampoco era desconocida en la poesía anterior. ${ }^{36}$ Por último cleri presidium se encuentra al inicio de dos hexámetros de Mateo de Vendôme, uno de su difundido Tobias (15) y otro de una epístola $(1,1,7)$, y en ambos casos forma parte de la alabanza de un prelado.

Otras de las diversas junturas utilizadas son más o menos habituales en la versificación dactílica: gaudens dare (v. 5) se emplea con frecuencia en interior de hexámetro, dare donum (v. 5) sobre todo en la cláusula, quicquid habebat (v. 7) también en ella y pius atque benignus (v. 3 ) en la parte final del hexámetro. Así mismo en las alabanzas medievales de cargos eclesiásticos es común la expresión nomine dignus. Aquí el poeta la ha aprovechado para incluir un juego con los dos significados de prelatus, palabra que aquí sustituye al presul de los vv. 1 y 9: por un lado, su significado etimológico como

\footnotetext{
35 Fernández Martínez 2012: 36.

36 Por ejemplo en Alcuino († 804): Lugentesque sui funus lacrimabile patris (carm. 1,622).
}

participio del verbo praefero («aquel al que se pone por delante de los demás, preferido, superior»); por otro, su significado medieval como sustantivo («prelado, obispo»). Así se señala que el obispo Pedro es digno tanto del cargo episcopal como de ser superior al resto, el preferido de Dios. Por último, funus es frecuente en la poesía funeraria y se suele emplear en ella como sinónimo de mors al igual que aquí.

Además de los mencionados lusus uerborum, el poeta se sirve de algunos otros adornos o figuras. Las más abundantes son las que afectan al aspecto fónico, muy del gusto de la época: por un lado, la aliteración, que se emplea para destacar la figura del finado o sus cualidades en presul Petrus Petri (v. 1), presule de Petro breuiter... metro (v. 9), petra per mea scribo metra (v. 10), y de forma más suave en paciens prelati (v. 4), términos que rodean la cesura pentemímeres, en dare donum (v. 5), donde se une a la figura etimológica, y en presidium promtus (v. 6), palabras situadas en torno a la diéresis del pentámetro; por otro, el homeotéleuton fuera de la propia rima: uia - pia (v. 2), egregius socius... pius (v. 3); así como la repetición de la misma sílaba en términos contiguos: alma Maria (v. 1). En el aspecto sintáctico, emplea el encabalgamiento entre los dos versos que forman los dos primeros pares del poema (vv. 1-2 y 3-4) y recurre al paralelismo entre las construcciones de los vv. 5-6 (omnibus hospicium / cleri presidium, gaudens... donum / promtus... bonum) y las del v. 8 (hic dare... renuit / mens dare... fuit). Asimismo hay un quiasmo entre los dos sintagmas sinónimos que cierran cada miembro del primer dístico (Alma María / Virgo pia).

En resumen, este epitafio presenta al obispo Pedro Pérez como personaje santo y excepcional entre el clero, e insiste especialmente en su extrema liberalidad, en la que se parece al santo titular de la capilla, Martín de Tours. Se trata de un poema salido de la pluma de un hombre culto y buen conocedor de la técnica métrica y las convenciones poéticas medievales, aunque mediocre en su genio y vigor poético. En efecto, la obra resulta convencional en todos sus aspectos menos en uno, que es más propio de la poesía sobre folio: la presencia en primera persona de la voz del anónimo poeta y sus breves indicaciones sobre la propia composición. Frente a tal convencionalidad sorprende enormemente la ausencia de uno de los elementos imprescindibles en todo titulus fúnebre, la fecha del óbito, quizás debido a que aún no se había producido este, porque su autor fue el propio prelado, que quería dejar resueltos sus asuntos fúnebres.

\section{DeCONSTRUYendo a PedRo PÉREZ: REVISIÓn CRÍtICA DE LA TRA-} DICIÓN HISTORIOGRÁFICA

Se debe a Gil González Dávila, primer historiador de la diócesis de Salamanca, el primer esbozo biográfico del obispo Pedro Pérez, que incluyó en su Historia de las antigüedades de la ciudad de Salamanca, publicada en la ciudad del Tormes en $1606 .{ }^{37} \mathrm{El}$ erudito abulense, miembro del cabildo de Salamanca durante un tiempo, ofreció una información limitada y errónea sobre este prelado, a quien, de entrada, consideró dominico, extremo este que, aunque mantenido por Gams y por Eubel con la repercusión propia de sus

37 González Dávila 1606: 239-241 (recogido de forma aún más sucinta en González Dávila 1618: 86). 
conocidos repertorios, ${ }^{38}$ apenas ha sido tenido en cuenta por la historiografía posterior y, de hecho, ha sido rotundamente desmentido por Beltrán de Heredia. ${ }^{39}$ El esbozo biográfico de González Dávila se basaba únicamente en las inscripciones de la capilla de San Martín y en las anotaciones del libro de aniversarios, limitándose a ofrecer una transcripción y glosa de su epitafio y a señalar que «Falleció en la era 1300 [año 1262], a 30 de abril», esto es, el año que figura en las pinturas murales del muro oriental de la capilla de San Martín y el día que figura su conmemoración en el libro de aniversarios, que, sin embargo, no tiene por qué coincidir necesariamente con el de su fallecimiento. Según González Dávila, su episcopado habría durado apenas un año, pues sitúa el tránsito del obispo anterior (Gonzalo en su consideración) en $1261 .{ }^{40}$

El estudio de Gil González Dávila mantuvo su vigencia hasta que en 1776 se publicó el Compendio histórico de la ciudad de Salamanca de Bernardo Dorado, donde, por vez primera, se abordó la realización de una biografía crítica del obispo Pedro Pérez «probada con auténticos documentos». ${ }^{41}$ Este sacerdote salmantino indagó en documentos contemporáneos del prelado, especialmente en los publicados en algunas de las muchas obras de erudición histórica que ya por entonces estaban a disposición de los estudiosos, pero también en aquellos conservados en el archivo catedralicio de Salamanca, lo que le condujo a realizar tres aportaciones fundamentales: en primer lugar, el encuadramiento cronológico del personaje: «egerció su dignidad desde mayo de 1246 hasta por octubre de $1264 »{ }^{42}$ en segundo lugar, el

38 Gams (ed.) 1873: 67; Eubel 1913: 428

39 Beltrán de Heredia 1970-1972: 1, 73, n. 28. Beltrán de Heredia basa su refutación en el hecho de que Pedro Pérez figure como arcediano antes de ser nombrado obispo, existiendo constancia de las casas que habitaba entonces, y en el hecho de que Pedro Pérez aparezca siempre en la documentación regia precedido únicamente del tratamiento "don".

40 González Dávila 1606: 235-238 (en similares términos González Dávila 1618: 84-85). El obispo Gonzalo no encuentra respaldo en la historiografía posterior. El más completo episcopologio salmantino de la Edad Media se encuentra en Beltrán de Heredia 1970-1972: 4, 519 540, siendo así mismo referencia obligada Aldea Vaquero et alii (dirs.) 1972-1975, 4, 2143-2144. En realidad, lo que hizo González Dávila fue desdoblar la personalidad de Pedro Pérez en dos figuras distintas: a saber, el obispo Pedro [II] y el obispo fray [sic] Pedro [III] Pérez, al introducir entre una y otra al obispo Gonzalo [VI]. Sobre el obispo Pedro II, que no es otro que el mismo Pedro Pérez que aquí nos interesa, v. González Dávila 1606: 205-234 (en similares términos González Dávila 1618: 81-84), donde se ocupa no tanto de este personaje como de los conventos de San Esteban y de San Francisco, que se consolidaron durante su episcopado en la ciudad de Salamanca.

41 Dorado 1776: 215-218.

42 Ibídem: 217. Bernardo Dorado se basó en un documento publicado por Enrique Flórez (1762: 505-507) para situar el inicio de su episcopado, cuando menos, en mayo de 1246 , pero ya el sabio agustino había advertido que la datación de este documento era errónea y debía posponerse (Flórez 1762: 236). De hecho, Julio González (19801986: 3, 327-328) lo ha fechado correctamente en 1248. Basándose en documentación salmantina que no precisa, Bernardo Dorado (1776: 216) señaló que «las actas o instrumentos capitulares nos le aseguran en su prelacía desde el año de 1247 ». Nuestro actual conocimiento de la documentación salmantina nos lo presenta por vez primera como obispo de Salamanca a 5 de enero de 1248 (v. infra n. 54), aunque pudiera serlo, en efecto, desde finales de 1247. No sucedió al obispo Martín Fernández (1229-1245), como quiere nuestro autor (Dorado 1776: 215), sino al efímero Mateo Reinal (1246-1247), quien sería sucesivamente obispo de Salamanca, de Cuenca y de Burgos (v. Beltrán de Heredia 1970-1972: 1, 71-73; 4, 520 y 521). En cuanto al final de establecimiento de su cursus honorum: «en el año 1226 (...) le vimos condecorado con las dignidades de canónigo y arcediano de esta Santa Iglesia y cancelario de nuestro monarca don Alfonso IX, cuyo exercicio le empezó a obtener desde el año de $1215 » ;{ }^{43}$ y en tercer lugar y de especial relevancia, la definición de una metodología de trabajo. Por supuesto, su estudio no está exento de errores, imprecisiones y omisiones, pero marca la pauta a seguir, aunque, por desgracia, las obras que se sucedieron durante más de un siglo no hicieron sino perpetuar los datos ofrecidos por Bernardo Dorado, sin profundizar en lo realmente valioso de su trabajo: su planteamiento metodológico. Nos referimos no solo a publicaciones como la nueva y severamente criticada versión de la obra de Bernardo Dorado, de $1861,{ }^{44}$ sino también a obras como la acreditada Historia de Salamanca de Manuel Villar y Macías, de $1887,{ }^{45}$ o como la titulada Episcopologio salmantino de Juan Antonio Vicente Bajo, de 1901. ${ }^{46}$

El siglo $x x$ debiera haber supuesto un punto de inflexión en el conocimiento del obispo Pedro Pérez como consecuencia de la labor de edición de amplias series documentales del periodo, intensa y crítica, como corresponde al momento de plena madurez académica y científica alcanzado por la Historia y por sus disciplinas auxiliares. Esta labor debiera haber propiciado un pleno abordaje del planteamiento metodológico de Bernardo Dorado, que no es sino el de la moderna historiografía. Comenzando por la documentación real, los estudios de referencia de Julio González sobre Alfonso IX o sobre Fernando III $^{47}$ o, más recientemente, el de Manuel González Jiménez sobre Alfonso $X^{48}$ han puesto a nuestra disposición series documentales prácticamente completas de los respectivos reinados. Continuando por la documentación local, a la catalogación del Archivo de la Catedral de Salamanca publicada por Florencio Marcos

su episcopado, hubo de ser necesariamente anterior a octubre de 1264 , pues, como veremos, el 21 de marzo de 1264 figura ya su sucesor Domingo Martínez, por lo que no se entienden las referencias de Bernardo Dorado (1776: 216 y 217), en justificación de su propuesta cronológica, al "testamento [de Pedro Pérez] que oy se conserva» o a la «vacante por el mes de octubre de el referido año [1264]», pues ni del uno ni de la otra existe el más mínimo indicio en nuestro actual conocimiento de la documentación salmantina.

43 Dorado 1776: 215 (así mismo, 98 y 205). Nuestro actual conocimiento de la documentación no nos permite afirmar ni que fuera canónigo de Salamanca en momento alguno, aunque conste un canónigo de este nombre documentado en 1220-1223 que, como veremos (v. infra n. 118), no es, en ningún caso, el arcediano de Salamanca que nos interesa (por otra parte, no tendría sentido acumular una canonjía y una dignidad en la misma iglesia), ni que fuera arcediano de Salamanca a la altura de 1226 (Dorado, en este caso, no alude al documento en que apoya su afirmación), aunque, como veremos, conste efectivamente con esta dignidad en el periodo de 1214 a 1221 y ¿1223? y pudiera seguir teniéndola perfectamente a la altura de 1226 . En cuanto a su desempeño de la cancillería de Alfonso IX, consta, como veremos, en los periodos de 1213 a 1221 y de 1224 a 1230 .

44 Girón (ed.) 1861: 145.

45 Villar y Macías 1887: 1, 385.

46 Vicente Bajo 1901: 55-56.

47 González 1944; González 1980-1986. En el presente trabajo la colección diplomática de Alfonso IX, incluida en el t. II de González 1944, será citada de forma abreviada CD Alfonso IX, seguida del número del documento correspondiente, y la colección diplomática de Fernando III, incluida en el t. III de González 1980-1986, será citada de forma abreviada CD Fernando III, seguida igualmente del número del documento correspondiente.

48 González Jiménez y Carmona Ruiz 2012. 
Rodríguez en $1962^{49}$ ha seguido la completa edición de su colección diplomática hasta $1300 .^{50}$ La situación es similar a propósito del Archivo de la Catedral de Orense, que, como veremos, también es relevante para nuestro objetivo. ${ }^{51}$ La documentación pontificia ha sido ampliamente escudriñada por Vicente Beltrán de Heredia en su bulario y en su cartulario de la Universidad de Salamanca, ${ }^{52}$ que, más allá de lo que prometen sus aparentemente modestos títulos, ni son una mera colección diplomática ni son, siquiera, una historia de la Universidad de Salamanca: son, más bien, una historia de la iglesia de Salamanca, a la que la alma mater salmantina estuvo inextricablemente unida en sus orígenes. Sobre estas bases, tanto Julio González como Vicente Beltrán de Heredia se enfrentaron, de hecho, a la tarea de redactar una biografía crítica actualizada del obispo Pedro Pérez, llegando a formulaciones diametralmente opuestas sobre el personaje que habremos de comentar más adelante..$^{53} \mathrm{En}$ cualquier caso, sus propuestas apenas han tenido repercusión, de manera que el paradigma biográfico de referencia del obispo Pedro Pérez sigue siendo el que Bernardo Dorado publicara hace casi doscientos cincuenta años.

\section{Construyendo a Pedro Pérez: términos CRonológicos Y LÍNEAS GENERALES DE SU EPISCOPADO}

Con este panorama se impone, de entrada, fijar los términos cronológicos de su episcopado. Pedro Pérez aparece por vez primera como obispo de Salamanca en un documento regio de 5 de enero de $1248 .^{54}$ Sucesivos documentos regios de 11 , de 15 y de 20 de enero de ese año señalan su condición de electus, ${ }^{55}$ que no se vuelve a indicar a partir del 27 de enero de ese año. ${ }^{56}$ Los documentos salmantinos lo presentan como obispo electo aún en febrero de $1248^{57}$

\footnotetext{
49 Marcos Rodríguez 1962.

50 Publicada en dos ocasiones: Martín Martín et alii 1977.
} Guadalupe Beraza et alii 2009. En el presente trabajo seguimos la edición de 2009, que citaremos de forma abreviada CD Salamanca, seguida del número del documento correspondiente.

51 La catalogación ha sido publicada en Duro Peña 1973. La completa edición de su colección diplomática hasta 1300 ha sido publicada en dos ocasiones: Duro Peña 1996; Vaquero Díaz y Pérez Rodríguez 2010. En el presente trabajo seguimos la edición de 2010, que citaremos de forma abreviada $C D$ Orense, seguida del número del documento correspondiente.

52 Beltrán de Heredia 1966-1967; Beltrán de Heredia 1970-1972.

53 González 1944: 1, 486-489 y 491; Beltrán de Heredia 19701972: 1, 73-76; 4, 520 y 521. Sus formulaciones no están exentas de pequeños errores, perfectamente disculpables por el volumen de información que manejan, unido a la vulgaridad onomástica del periodo, a menudo desesperante.

54 CD Fernando III: 751. En el anterior documento regio en que figura un obispo de Salamanca, dado a 24 de diciembre de 1246, este, según Julio González, es Martín, v. Ibídem: 745, pero debe de tratarse de una mala interpretación del nombre (patente así mismo en CD Salamanca: 219), pues el obispo Martín Fernández renunció a su sede en 1245 , estando recién nombrado a esas alturas obispo de Salamanca Mateo Reinal, el predecesor de Pedro Pérez, v. Beltrán de Heredia 1970-1972: 1, 71-73.

55 CD Fernando III: 753-755.

56 Ibídem: 756. Todos estos documentos están dados en el real de Sevilla, lo cual, dada la tipología documental de que se trata — privilegios rodados-, no significa que Pedro Pérez, obispo de Salamanca, estuviese físicamente allí acompañando al monarca en la campaña.

57 CD Salamanca: 225. y como obispo de pleno derecho solo en mayo de $1248 . .^{58}$ Es muy posible que su nombramiento se produjera a finales de 1247, pero carecemos de constancia documental de ello: Beltrán de Heredia aclaró que la fecha de 28 de agosto de 1247 que suele figurar como inicio de su mandato en los episcopologios al uso corresponde, en realidad, al traslado de su predecesor, Mateo Reinal, a la sede de Cuenca, constando, de hecho, sede vacante en Salamanca en septiembre de $1247 .{ }^{59}$ Carecemos de testimonios documentales entre esa fecha y enero de 1248 que permitan precisar más.

Según la documentación salmantina, Pedro Pérez continuaba aún en el cargo en febrero de $1263 .{ }^{60}$ El 21 de marzo de 1264 era ya obispo de Salamanca su sucesor, Domingo Martínez, ${ }^{61}$ quien el 24 de abril de 1263 era solo deán. ${ }^{62}$ Puesto que un documento regio señala a Pedro Pérez como obispo de Salamanca a 23 de febrero de $1264,{ }^{63}$ el final de su episcopado, bien fuera por muerte bien fuera por renuncia (era entonces en cualquier caso un hombre de edad muy avanzada), ${ }^{64}$ hubo de producirse entre esa fecha y el 21 de marzo de $1264 .{ }^{65}$ Dorado hizo alusión a su testamento (se entiende que de 1264, pues se refiere a él para justificar el término de su episcopado), pero, a día de hoy, este documento o bien no ha sido localizado o bien no se conserva. ${ }^{66}$

Los términos cronológicos documentados del episcopado de Pedro Pérez en Salamanca son, pues, el 5 de enero de 1248 y el 23 de febrero de 1264, estimable periodo de dieciséis años del que se suele recordar el definitivo asentamiento de los dominicos en la ciudad al serles cedida por

58 Ibídem: 226.

59 Beltrán de Heredia 1970-1972: 1, 73, n. 28 (donde señala que «dada la situación delicada en que se encontraba la diócesis, tal vez [el nombramiento del nuevo obispo] se aplazó por lo menos hasta octubre»). La constancia documental de sede vacante en Salamanca en septiembre de 1247 en CD Salamanca: 222-223.

60 CD Salamanca: 305. Un documento de 10 de agosto de 1263 menciona al obispo de Salamanca sin especificar su nombre, v. Ibídem: 307 , si bien como comprobaremos inmediatamente solo puede referirse a Pedro Pérez, v. infra n. 63.

61 Ibídem: 308.

62 Ibídem: 306. Lo fue, cuando menos, desde 1243 (esto es, durante todo el episcopado de Pedro Pérez), v. Ibídem: 205

63 Berganza 1721: 485-486.

64 Beltrán de Heredia 1970-1972: 1, 76, contempla ambas posibilidades, si bien refiriéndolas "hacia $1263 »$. Si el final de su episcopado se hubiera producido por renuncia, la fecha de 30 de abril en que, según el libro de aniversarios, se le conmemoraba, podría ser, en efecto, la fecha de su muerte (acaeciera esta en 1264 o en algún año inmediatamente posterior). La posibilidad de la renuncia se manifiesta en una carta de quien habría de ser su sucesor, el deán Domingo Martínez, al obispo de Urgel, Abril Peláez, que comentamos más adelante, v. infra n. 74.

65 En la documentación regia de este periodo, dada en Sevilla, v. González Jiménez y Carmona Ruiz 2012: 301-303, no encontramos documento alguno que nos permita precisar más.

66 Dorado 1776: 216. Manuel González García (1973: 111) menciona como «testamento de Don Pedro, obispo de Salamanca (A.C.S., caj. 3, leg. 1, núm. 48, 16-agosto-1257)» un documento que no es sino una donación de unas casas al cabildo de Salamanca por parte de su prelado con carga de aniversarios, v. CD Salamanca: 272. Estas casas, que sunt iuxta cimiterium ecclesie cathedralis et ex una parte sunt domos episcopales, et ex alia parte sunt domus que fuerunt domni Velasci et domne Matris, no coinciden con aquellas de cuya renta se tomará una parte para la celebración de su aniversario a 30 de abril, «vnas casas en la rúa Nueva, commo van de las escuelas mayores al desafiadero, a la mano ysquierda», v. Archivo de la Catedral de Salamanca, Caj. 67, leg. 3, núm. 1, f. 87v. 
parte del obispo y del cabildo la iglesia de San Esteban en $1256^{67}$ y del que se puede destacar el punto álgido alcanzado por las tensiones entre clero gallego y clero autóctono que caracterizaron a la iglesia salmantina durante los siglos XII y XIII. ${ }^{68}$ En efecto, Santiago de Compostela, en tanto que sede de la que dependía la iglesia de Salamanca, ejercía un gran ascendiente sobre esta, existiendo entre sufragánea y metropolitana no solo una estrecha relación de dependencia jurisdiccional y espiritual, sino también intelectual, que tuvo, no obstante, su vertiente más espinosa en el hecho de que el clero compostelano contemplara la iglesia de Salamanca como un ámbito donde obtener beneficios y donde hacer carrera en perjuicio tanto del clero autóctono, que casi siempre veía frustradas sus legítimas aspiraciones de promoción, como del servicio divino, pues con no poca frecuencia el clero foráneo desatendía la residencia. En 1245 las tensiones entre el clero gallego, que ejercía una posición de dominio en el cabildo y en el episcopado, y el clero autóctono forzaron la redacción de unas constituciones por parte del cardenal castellano Gil de Torres, cardenal diácono de los Santos Cosme y Damián, acerca de la colación de beneficios en la Catedral. ${ }^{69}$ Estas constituciones, que pretendían equilibrar la situación, fueron sancionadas inmediatamente por Inocencio IV, ${ }^{70}$ pero su implementación fue fuente de conflictos enconados. Pedro Pérez tuvo que lidiar con esta situación durante su prelatura. En 1255 denunció ante el papa unas supuestas cartas del cardenal Gil de Torres, recientemente fallecido, que hacían extensiva a toda la diócesis de Salamanca las constituciones dictadas en 1245 para su Catedral (en perjuicio evidente del clero gallego). ${ }^{71}$ Al final, debido acaso a su edad avanzada, Pedro Pérez causa la impresión de haberse visto desbordado por las circunstancias. En 1261 una bula de Urbano IV emitida a instancias del cabildo salmantino, controlado por el clero gallego encabezado por el deán e inmediato obispo Domingo Martínez, oriundo del actual concejo coruñés de Mellid, ${ }^{72}$ anulaba una bula de su antecesor, Alejandro IV, que dejaba la futura elección del obispo en manos de la Santa Sede en lugar de en las del cabildo, según costumbre. ${ }^{73}$ En este documento se dice que venerabilis frater noster Salamantinus episcopus, adeo erat grauatus senio, quod de morte dubitabatur ipsius. El mismo Domingo Martínez, en una carta

67 Cuervo (ed.) 1914-1915: 3, 629. Data así mismo del episcopado de Pedro Pérez el estatuto de organización y de dotación de la Universidad de Salamanca, dado por Alfonso X a 8 de mayo de 1254, v. Beltrán de Heredia 1970-1972: 1, 604-606. Este estatuto configuró y consolidó esta importante institución académica que había sido fundada por Alfonso IX a finales de 1218 o a principios de 1219 , pero no podemos determinar si nuestro obispo tuvo alguna participación en la gestación del mismo.

68 Expuestas y comentadas minuciosamente por Vicente Beltrán de Heredia (1970-1972: 1, 59-68).

69 CD Salamanca: 214. Comenta este documento Beltrán de Heredia 1970-1972: 1, 61-63.

70 CD Salamanca: 217.

71 Beltrán de Heredia 1970-1972: 1, 63-64.

72 Sus raíces se ponen de manifiesto en su testamento, v. $C D$ Salamanca: 321, donde deja "Al ospital de Furelos, o foy criado, xx morabedís».

73 CD Salamanca: 297. Comenta este documento Beltrán de Heredia 1970-1972: 1, 75, que entiende la bula revocada de Alejandro IV como producto de una maniobra del clero autóctono para neutralizar el ascendiente del clero gallego. sin fecha que se pretendía discreta (Lecta littera rumpatur), dirigida a su paisano y antiguo compañero en la iglesia de Salamanca Abril Peláez, a la sazón obispo de Urgel (12571269), se queja de que Episcopus noster irrequisito consilio Gallecorum proponit romanam curiam visitare, et apud nos causa penitus ignoratur. Verum quia malum habuit principium, sicut scitis, credimus ipsum proponere resignare, por lo que pide a Abril Peláez que recurra a sus contactos en la curia ne aliquis extraneus nobis in nostra ecclesia supplantetur. ${ }^{74}$ No sabemos si Pedro Pérez llegó a emprender el viaje o a renunciar a la sede de Salamanca antes de que la muerte se ocupara de él. Lo que sabemos es que su azaroso episcopado terminó en 1264 , allanando el camino al episcopado de Domingo Martínez, y, aunque aún se sucederían en la sede salmantina algunos clérigos gallegos, su ascendiente fue mermando a lo largo de la segunda mitad del siglo XIII hasta alcanzar una situación normalizada ca. 1300.

El periplo vital de Pedro Pérez como obispo de Salamanca se puede reconstruir razonablemente, aunque con algunas incertidumbres, con algunas circunstancias sujetas a interpretación... ${ }^{75} \mathrm{El}$ problema surge cuando intentamos retrotraernos más allá de 1248 en la vida de este hombre que mereció alcanzar la mitra salmantina y que, a la altura de 1261, adeo erat grauatus senio. Recordemos que Dorado había dicho que «en el año 1226 (...) le vimos condecorado con las dignidades de canónigo y arcediano de esta Santa Iglesia y cancelario de nuestro monarca don Alfonso IX, cuyo exercicio le_empezó a obtener desde el año de $1215 »{ }^{76}$ Indagando estas referencias surge la necesidad metódica de analizar por separado dos «unidades biográficas» diferenciadas para, posteriormente, poder considerar en qué medida pueden corresponder a un único individuo.

Pedro Pérez, CANCiller de Alfonso IX de León (1213-1221 Y 1224-1230), DOCUMENTADO ENTRE 1203 Y 1242

Los arzobispos de Santiago de Compostela eran los cancilleres naturales del reino de León, aunque con frecuencia delegaban sus funciones como tales en persona o personas de su confianza y de la del monarca. ${ }^{77}$ El Pedro Pérez que desempeñó el puesto de canciller de Alfonso IX de León en dos periodos distintos, a saber, el primero entre 1213 y $1221^{78}$ y el segundo entre 1224 y 1230 (año en que falleció

74 Villanueva 1850: 238. Comentan este documento Ibídem: 97-98, y Beltrán de Heredia 1970-1972: 1, 77-78. Abril Peláez había sido arcediano en Salamanca, donde consta como tal en 1243 , v. CD Salamanca: 207-208.

75 Para referencias a Pedro Pérez en su calidad de obispo en la documentación salmantina, v. CD Salamanca: 225-235, 238-262, 264-266, 268-300, 303 y 305 (y, con posterioridad al final de su episcopado, 318).

76 V. supra n. 43.

77 Lucas Álvarez 1993: 512-513.

78 Se ocupan de su perfil como canciller González 1944: 1, 487 489 y 491, y Lucas Álvarez 1993: 517-518. El primer periodo consta entre las fechas extremas de 10 de junio de 1213, v. CD Alfonso IX: 292, y de 14 de noviembre de 1221, v. Ibídem: 415. Julio González señala el inicio de este primer periodo el 8 de diciembre de 1213, puesto que en documentos anteriores se titula vicecanciller (el 10 de junio de 1213 se titula, no obstante, canciller), v. González 1944: 1, 488-489, pero, en realidad, esto ocurre igualmente de manera ocasional en documentos posteriores hasta 1215, v. CD Alfonso IX: 296-298, 302, 313 y 319. Se refiere así mismo a Pedro Pérez como vicecanciller su tío Fruela, de quien nos ocuparemos enseguida, en un documento salmantino de 3 de febrero de 1214, v. CD Salamanca: 139. 
el monarca) ${ }^{79}$ se encuentra documentado al servicio de esta institución desde $1203 .^{80}$ Consta primeramente como notario y, en su caso, como escribiente, tareas en que se encuentra documentado hasta 1209 , momento a partir del cual se produce un vacío documental hasta su primer desempeño de la cancillería a partir de $1213 .{ }^{81}$ Entre los dos periodos de su desempeño se hizo cargo de la cancillería el maestro Bernardo, deán de Santiago de Compostela, que en 1224 sería nombrado arzobispo de Santiago de Compostela. ${ }^{82}$

La actuación como notario de Pedro Pérez (1203-1209) se corresponde fundamentalmente con el periodo en que estuvo al frente de la cancillería Fernando, deán de Santiago de Compostela (1203-1210), de quien fue su más estrecho colaborador, ${ }^{83}$ pero quien a buen seguro lo introdujo en este organismo fue su tío Fruela, que venía trabajando en él en calidad de notario desde 1187, llegando a ejercer como vicecanciller en 1200 , como tenente de la cancillería junto a Pedro Suárez en 1202-1203 (justo cuando se produjo el ingreso de Pedro Pérez) y de nuevo como vicecanciller en $1204 .{ }^{84}$ Los oficiales de la cancillería regia solían ser recompensados con beneficios eclesiásticos en las más importantes iglesias del reino. Estos beneficios les reportaban rentas, reconocimiento social y, en su caso, un ámbito de retiro apropiado cuando abandonasen el servicio de la institución. Ese fue el caso de Fruela, deán de León (1207$1219)^{85}$ y maestrescuela de Salamanca $(1207-1220),{ }^{86}$ y ese fue también, como veremos, el caso de Pedro Pérez.

79 Entre las fechas extremas de 31 de agosto de 1224, v. CD Alfonso IX: 443, y de 1 de agosto de 1230 (último documento que presenta una data completa), v. Ibídem: 620.

80 Su primera ocurrencia documental data del 22 de febrero de 1203, v. CD Alfonso IX: 173. En ella figura así: Petrus Petri, regis notarius, scripsit. Archidiacono Petro Suerii et domino Froyla tenentibus cancelleriam de domino archiepiscopo. González 1944: 1, 488, dice que Pedro Pérez entró al servicio de la cancillería regia en 1202, «en la flor de su edad», pero no encontramos documentos anteriores al referido.

81 Se ocupan de su perfil como notario González 1944: 1, 486-487, y Lucas Álvarez 1993: 521. Corresponde a este periodo un documento de 25 de abril de 1205 no recogido por González que se conserva en Salamanca, v. CD Salamanca: 123. El último documento en que aparece como notario data del 20 de abril de 1209, v. CD Alfonso IX: 248. González dice que Pedro Pérez se ausentó de la cancillería durante dos años y medio y que, de manera a su juicio significativa, se ausentó coincidiendo con el final del desempeño de la cancillería por parte de Fernando, deán de Santiago de Compostela, pero el vacío documental que se constata es de cuatro años, de abril de 1209 a junio de 1213, y Fernando estuvo al frente de la cancillería hasta junio de 1210. ¿Pudo deberse esta ausencia a un periodo de formación, necesario para adquirir las competencias que se requerían para su futuro desempeño de la cancillería?

82 González 1944: 1, 489-490; Lucas Álvarez 1993: 518-519.

83 González 1944: 1, 485-486; Lucas Álvarez 1993: 515-516. No obstante, Pedro Pérez entró en escena con anterioridad al inicio del desempeño de la cancillería por parte de Fernando, cuyo primer documento como canciller data del 31 de mayo de 1203, v. CD Alfonso IX: 176.

84 González 1943: 171-172; González 1944: 1, 483-484 y 486; Lucas Álvarez 1993: 361 y 519-520. Beltrán de Heredia 1970-1972: 1, 68-69, lo presenta como pariente de Pedro Suárez de Deza, canciller de Fernando II de León (1165 y 1182), obispo de Salamanca (1166-1173) y arzobispo de Santiago de Compostela (1173-1206), v. González 1943: 168 y 171; Lucas Álvarez 1993: 354. Para Beltrán de Heredia Pedro Suárez de Deza habría situado a Fruela tanto en la cancillería regia como en la iglesia de Salamanca, pero no nos consta documentación que acredite este parentesco, que solo podemos asumir a título de conjetura.

85 Fernández Catón 1991: 193-196, 199-203, 216-218, 254-255, 327-329, 342-343 y 353-355; CD Salamanca: 126.

86 CD Salamanca: $126,135,139$ y $147-148$.
Que Fruela era tío de Pedro Pérez es indudable. Lo declara Fruela cuando, a 3 de febrero de 1214, en su calidad de maestrescuela de Salamanca, dona unas casas in calle illo qui descendit de ecclesia Sancte Marie uersus ecclesiam Sancti Cipriani y una heredad in Cardanosa al cabildo de Salamanca para la celebración de su aniversario, con la condición de que pueda disfrutarlas en vida y de que post obitum meum Petrus Petri, uicecancellarius regis, et Pelagius, nepotes mei, teneant illas similiter in uita sua, et in die anniversarii mei dent de illis capitulo Salamantino IIIlor morabitinos: duos de domibus ipsis et duos de ipsa hereditate. ${ }^{87}$ La situación de Fruela en Salamanca pudo allanar el camino al inmediato acceso de Pedro Pérez a uno de los arcedianatos de esta iglesia, en coincidencia, significativamente, con su encumbramiento a la cabeza de la cancillería regia.

En efecto, Pedro Pérez labró su carrera eclesiástica durante sus años al servicio de la cancillería regia. ${ }^{88}$ Durante el periodo en que sirvió en ella como notario se tituló ocasionalmente canónigo de Santiago de Compostela (en cuatro documentos de 1208 y de 1209$)^{89}$ y canónigo de Orense (en tres documentos de 1209). ${ }^{90}$ Ya como canciller, el título de canónigo de Santiago de Compostela lo empleó de nuevo ocasionalmente en $1214^{91}$ y regularmente a partir de 1224 (hasta el final de su desempeño en 1230). ${ }^{92}$

Durante su primer periodo como canciller (12131221), Pedro Pérez se tituló arcediano de Salamanca

87 Ibídem: 139. Con anterioridad, a 13 de marzo de 1213, Pascasio, chantre de Salamanca, vende a Fruela, maestrescuela de Salamanca, una casa de Pisonibus (...) circa ripam fluuii Tormis que este dona de inmediato al cabildo de Salamanca pro anima uestra [de Fruela: es Pascasio quien otorga el documento en primera persona] et pro anniuersario nepotis uestri [de Fruela] Iohannis Martini et consobrini eius Pelagii, qui sunt in claustro prefate sedis in uno tumulati, v. Ibídem: 135. Este Pelayo, primo de Juan Martínez, sobrino de Fruela, maestrescuela de Salamanca, ha de ser necesariamente distinto de Pelayo, sobrino de Fruela, maestrescuela de Salamanca, citado vivo en 1214 en el documento comentado en el cuerpo del texto.

88 Dado el parentesco de Pedro Pérez con Fruela, deán de León y maestrescuela de Salamanca, cabe preguntarse si el Petrus Petri clericus que figura junto a Fruela entre los testigos de un documento salmantino de 22 de abril de 1207 (con anterioridad, por tanto, a que el Pedro Pérez al servicio de la cancillería regia empiece a titularse canónigo) es, como parece, el personaje que nos interesa, v. CD Salamanca: 126.

89 CD Alfonso IX: 231, 234 y 247-248. Lucas Álvarez 1993: 521, dice que era canónigo de Santiago de Compostela ya en 1203 , pero no encuentro respaldo documental para esta afirmación.

90 CD Alfonso IX: 239-241. Lucas Álvarez 1993: 516 y 521, expresa ciertas dudas acerca de que el notario Pedro Pérez que se titula canónigo de Orense en 1209 sea el notario Pedro Pérez que se titula canónigo de Santiago de Compostela en 1208-1209. Considerando los vínculos del futuro canciller Pedro Pérez con Orense que enseguida detallaremos, pensamos que es indudable, siendo el suyo un caso más de acumulación de prebendas. Canónigo o canónigos de este nombre están documentados en Orense en 1197, v. CD Orense: 65 , en 1205, v. Ibídem: 100, en 1207, v. Ibídem: 107-108, en 1214, v. Ibídem: 130 y en 1215, v. Ibídem: 132-133, sin que se pueda asegurar cuáles de estas referencias atañen al personaje objeto de nuestro interés, máxime si, como acabamos de sugerir, en 1207 era solo clérigo, v. supra n. 88, caso en el que solo podrían corresponderle las de 1214-1215.

91 En un único documento de 9 de septiembre de 1214, v. CD Alfonso IX: 313.

92 Primer documento de 14 de diciembre de 1224 , v. CD Alfonso IX: 448. 
ocasionalmente en $1214^{93}$ y regularmente a partir de 1215 hasta el final de su desempeño en $1221 .{ }^{94}$ En la documentación salmantina aparece como tal en documentos de 8 de febrero de 1220 y de 9 de junio de $1220^{95}$ y en un documento sin data completa de 26 de diciembre para el que se propone su correspondencia al año $1223 .{ }^{96}$

Durante su segundo periodo como canciller (12241230), Pedro Pérez se tituló maestrescuela de Orense, amén de, según se ha indicado, canónigo de Santiago de Compostela. ${ }^{97}$ En 1229-1230 el título de maestrescuela de Orense alterna ocasionalmente con el título de arcediano de Orense. ${ }^{98}$ En la documentación orensana aparece como maestrescuela a partir del 19 de diciembre de $1219^{99}$ y como arcediano a partir del 15 de enero de $1231 .^{100}$

Que en este segundo periodo como canciller Pedro Pérez no se titulase arcediano de Salamanca no supone, en absoluto, que hubiese resignado esta dignidad: no es extraño que un individuo que acumula varios beneficios eclesiásticos exprese solo aquellos que considere más relevantes en cada momento y, de la misma manera que en 1219-1221, durante su primer periodo como canciller, no aludió nunca a su calidad de maestrescuela de Orense, en 1224-1230, durante su segundo periodo como canciller, no aludió nunca a su calidad de arcediano de Salamanca, ${ }^{101}$ acaso porque las circunstancias le habían llevado a sentirse especialmente próximo a la iglesia de Orense, sobre todo tras la desaparición de la documentación, seguramente por fallecimiento, de su tío Fruela en $1220 .{ }^{102}$

93 En un único documento de 19 de mayo de 1214, v. CD Alfonso IX: 308. González 1944: 1, 489, dice que accedió a esta dignidad «probablemente por voluntad de sus parientes y para ocupar la vacante de don Cipriano». Este Cipriano, arcediano de Salamanca, había fallecido a la altura del 3 de febrero de 1214, v. CD Salamanca: 139, cuando Fruela, maestrescuela de Salamanca, tío de Pedro Pérez, vicecanciller del rey, dona al cabildo de Salamanca las casas quas emi de heredibus archidiaconi domni Cipriani in calle illo qui descendit de ecclesia Sancte Marie versus ecclesiam Sancti Cipriani, estando en realidad documentado entre 1152 y 1182, v. Ibídem: 18-19, 21, 33, 63, 67-68, $72,76,79-82$ y 84 . Cipriano, arcediano de Salamanca, parece pertenecer por tanto a un periodo bastante anterior al que aquí nos ocupa, de manera que encontramos difícil y arriesgado establecer un vínculo directo entre su muerte y el acceso de Pedro Pérez a un arcedianato en Salamanca.

94 Primer documento de 13 de enero de 1215 , v. CD Alfonso IX: 316. Solo en dos documentos de este periodo se omite su condición de arcediano de Salamanca, v. Ibídem: 317 y 367.

95 CD Salamanca: 147-148.

96 Ibídem: 158.

97 Solo en tres documentos de este periodo se omite su condición de maestrescuela de Orense, v. CD Alfonso IX: 445 y 449-450. En el último, no obstante, se le denomina magister.

98 Este aparece en documentos de 31 de mayo de 1229, v. $C D$ Alfonso IX: 600, y de 1 de agosto de 1230 (último documento que presenta una data completa), v. Ibídem: 620. El título de maestrescuela de Orense aparece por última vez en un documento de 20 de julio de 1230, v. Ibídem: 619. En la documentación orensana figura Munio como maestrescuela a partir del 15 de enero de 1231, v. CD Orense: 246.

99 CD Orense: 143.

100 Ibídem: 246.

101 Como anteriormente indicamos, Dorado 1776: 215, dice que consta como arcediano de Salamanca a la altura de 1226 , pero no especifica en qué fuente apoya su afirmación y, desde luego, esta no se identifica en nuestro actual conocimiento de la documentación salmantina.

102 Recordemos que Fruela, deán de León y maestrescuela de Salamanca, está documentado hasta 1220 , v. supra nn. 85-86. Yerra,
En efecto, durante el periodo 1221-1224, en el que, por circunstancias que se nos escapan, permaneció alejado de la cancillería regia, Pedro Pérez está abundantemente documentado en Orense en calidad de maestrescuela ${ }^{103} y$, concluido su trabajo en la cancillería regia en 1230 , reaparece de nuevo en Orense en calidad de arcediano, estando documentado como figura prominente de su iglesia hasta el 10 de septiembre de $1242 .{ }^{104}$

Su vinculación con la iglesia de Orense coincide con el largo episcopado del reputado canonista Lorenzo Hispano (1218-1248), formado en la prestigiosa Universidad de Bolonia, donde llegó a impartir clases. ${ }^{105}$ Pedro Pérez debió de sucederle en la dignidad de maestrescuela, en la que Lorenzo consta en 1218, inmediatamente antes de su exaltación al obispado, ${ }^{106}$ y gozar enseguida del aprecio de su prelado, que en el primer periodo de estancia efectiva de Pedro Pérez en Orense (1221-1224) lo nombró su procurador en los contenciosos que mantenía con el caballero Pedro Fernández, ${ }^{107}$ con el concejo de Castrotorafe y con la Orden de Santiago ${ }^{108}$ De esta manera el obispo Lorenzo reconocía en Pedro Pérez una doble capacidad, social y profesional: capacidad social para representarlo y capacidad profesional para entender en negocios jurídicos. En 1227 Pedro Pérez fue nombrado albacea del deán de Orense Oerio Ordóñez, quien, además, le dejó en su testamento una copa de plata (ciphum meum argenteum minorem). ${ }^{109}$ En el segundo periodo de estancia efectiva de Pedro Pérez en Orense (1231-1242), lo encontramos a menudo actuando en nombre del deán ${ }^{110} \mathrm{o}$ del obispo ${ }^{111}$ como cabeza efectiva de la iglesia de Orense. En este periodo realiza, así mismo, a título particular varias operaciones de compra o de aforamiento de derechos reales en Orense y en sus inmediaciones, ${ }^{112}$ hasta que, de manera brusca, desaparece de la documentación a partir del 10 de septiembre de 1242.

La relación de beneficios eclesiásticos detentados por el Pedro Pérez canciller, documentado entre los años 1203 y 1242 , es, pues, como sigue: ${ }^{113}$

- Canónigo de Santiago de Compostela, 1208-1209, 1214 y $1224-1230$.

- Canónigo de Orense, 1209.

- Arcediano de Salamanca, 1214-1221, ¿1223?

por tanto, Beltrán de Heredia 1970-1972: 1, 70, cuando sitúa su muerte $c a .1214$, apuntando a la misma como causa del acceso de su sobrino Pedro Pérez a un arcedianato en Salamanca.

103 CD Orense recoge diez documentos de este periodo $(152,154$, $157,161,164-166,169-170$ y 173$)$ frente a solo dos del periodo $1219-$ 1221 (143 y 145) y a solo tres del periodo $1224-1230(185,187$ y 225$)$.

104 No hasta 1243, como afirma Lucas Álvarez 1993: 518, quien no pudo tener a su disposición la completa edición de la colección diplomática de Orense hasta 1300. CD Orense recoge veintidós documentos del periodo 1231-1242 (246, 250, 265-266, 273, 279-281, 283, 285$290,292,309,316,318-319$ y 322-323).

105 García García 1956.

106 Ibídem: 12-14. El documento en CD Orense: 139.

107 CD Orense: 152. Sobre este pleito, v. Ibídem: 148 y 154.

108 Ibídem: 164. Sobre estos pleitos, v. Ibídem: 154, 163, 165-167 y 246.

109 Ibídem: 187.

110 Ibídem: 266, 279-281, 287-290 y 292.

111 Ibídem: 316, 318 y 322.

112 Ibídem: 265, 273, 283, 319 y 323.

113 Indicamos únicamente los años en que consta fehacientemente en cada uno de ellos. 
- Maestrescuela de Orense, 1219-1230.

- Arcediano de Orense, 1229-1242.

Durante su desempeño de la cancillería regia Pedro Pérez empleó abundantemente a clérigos de Salamanca y de Orense. ${ }^{114}$

De su entorno familiar poseemos unos pocos datos. Pedro Pérez es, como sabemos, sobrino de Fruela, deán de León y maestrescuela de Salamanca y su más que probable mentor en la cancillería regia y en la iglesia de Salamanca. En consecuencia, Pedro Pérez ha de ser hermano o primo de los restantes sobrinos de Fruela que nos es dado conocer a través de la documentación: Pelayo, vivo a la altura de 1214, y Juan Martínez, fallecido a la altura 1213 (y acaso, así mismo, del primo de este: Pelayo, fallecido a la altura de 1213). Los parientes difuntos estaban enterrados en el claustro de la Catedral de Salamanca. ${ }^{115}$ Además, Pedro Pérez es tío del maestro Fernando, arcediano de Salamanca, según declara Alfonso IX Ilamándolo alumpno meo (entendemos que en el sentido de "criado mío») en un documento de 26 de diciembre de ¿1223? por el que le da unas propiedades en Salvatierra que fueron de avunculus eius archidiaconus Petrus Petri. ${ }^{116}$

En contra de las afirmaciones de Julio González y de Vicente Beltrán de Heredia, Pedro Pérez no es, en absoluto, sobrino de Gonzalo Fernández, obispo de Salamanca (11991226). ${ }^{117}$ Ciertamente, a 9 de junio de 1220 este prelado donó una serie de propiedades al cabildo de Salamanca manteniendo el usufructo de las mismas durante su vida y estableciendo que si Petrus Petri canonicus, nepos meus, post exitum vite mee superstes fuerit, tam ipsam ecclesiam quam dictas domos et hereditatem de Miranda in tota vita sua pacifice teneat et annuatim soluat canonicis vnun morabitinum, pero nuestro Pedro Pérez se titulaba ya arcediano de Salamanca a estas alturas y, como tal (Petrus Petri archidiaconus), figura entre los confirmantes del documento por parte del cabildo de Salamanca. ${ }^{118}$

Pedro Pérez, obispo de Salamanca (1248-1264), DoCumenTADO ENTRE 1243 Y 1264

Del Pedro Pérez que consta como obispo de Salamanca entre 1248 y 1264 , cuya trayectoria en este cargo hemos trazado con anterioridad, solo podemos afirmar con absoluta seguridad que fue arcediano de esta iglesia antes de asumir la prelatura de la misma: en 1253 , en la venta de

114 González 1944: 1, 490-492; Lucas Álvarez 1993: 521-525.

115 V. supra n. 87. No nos ha sido posible seguir la pista de estos individuos.

116 CD Salamanca: 158 El maestro Fernando figura así mismo como arcediano de Salamanca en un documento de ¿1224?, v. Ibídem: 160. En un documento de noviembre de 1235 figura como testigo "Rodrigo lohannis mayordomo que fu del arcidiano maestre Fernando», v. Ibídem: 192.

117 González 1944: 1, 488; Beltrán de Heredia 1970-1972: 70 y 74. Julio González sospecha que Fruela, deán de León y maestrescuela de Salamanca, fuese hermano de Gonzalo Fernández, obispo de Salamanca, pero, como indicamos en el cuerpo del texto, no existe base para la elaboración de un vínculo familiar entre estos individuos a partir de la figura de Pedro Pérez, arcediano de Salamanca.

118 CD Salamanca: 148. El canónigo de Salamanca Pedro Pérez, distinto del arcediano de Salamanca Pedro Pérez, reaparece en un documento de 1223, v. Ibídem: 157. unas casas en la judería, se mencionan ille domus in quibus solebat morari episcopus domnus Petrus Petri, quando erat archidiaconus. ${ }^{119}$ Un documento salmantino de 27 de marzo de 1243, al mencionar entre los testigos a varios arcedianos, cita a P. Petri de Medina, ${ }^{120}$ indicándonos de esta manera cuál de los cuatro arcedianatos existentes entonces en Salamanca (Alba y Salvatierra, Ledesma, Medina y Salamanca) desempeñó el futuro obispo Pedro Pérez. Con esta identificación, podemos referir a Pedro Pérez la noticia recogida por Beltrán de Heredia de que el deán de Salamanca (el conocido Domingo Martínez) y el arcediano de Medina, acompañados por el arcediano de Alba y Salvatierra y por varios canónigos, viajaron a Roma en calidad de procuradores del cabildo de Salamanca para entender en el asunto de la sucesión del obispo Martín Fernández, que había renunciado a la mitra en $1245 .{ }^{121}$ Este viaje, que debió de ser más bien a Lyon, donde se encontraba la curia en ese momento, hubo de producirse necesariamente entre ese año y 1246 , en que fue nombrado finalmente su sucesor.

La última noticia que podemos referir a Pedro Pérez en su calidad de arcediano de Medina resulta un tanto extraña: se encuentra en el testamento de su sucesor, el obispo Domingo Martínez, dado en Salamanca a 21 de enero de 1267, que menciona entre las posesiones de que dispone el prelado «la casa que está hy logo çerca la Figal que compré del arçidiano don Pedro Pérez e foron de Eluira, coxa, et tienlas agora el dayán de mía mano». ${ }^{122}$ Sorprende la más que probable referencia a su predecesor como arcediano, incluso aun cuando Domingo Martínez le hubiese comprado estas casas cuando Pedro Pérez era arcediano. Ciertamente, este personaje tuvo sus diferencias con Pedro Pérez, manifiestas en la carta que dirigió a su antiguo compañero en la iglesia de Salamanca Abril Peláez, obispo de Urgel, que comentamos con anterioridad, pero estas diferencias no justifican lo que, quizás de manera exagerada, podríamos interpretar como una especie de degradación post mortem.

De su entorno familiar apenas podemos aportar noticias. Con posterioridad al final de su episcopado se menciona a "dona Orraca, hermana del obispo don Pedro». ${ }^{123}$ Beltrán de Heredia afirmó que su homónimo Pedro Pérez, deán de Salamanca, documentado abundantemente a finales del siglo XIII, era probablemente su sobrino o pariente, ${ }^{124}$ pero puesto que esta afirmación se basa únicamente en la coincidencia de sus nombres, vulgares y recurrentes, entendemos que no podemos asumirla más allá de la conjetura.

119 Ibídem: 249

120 Ibídem: 207

121 Beltrán de Heredia 1970-1972: 1, 72. El documento en Beltrán de Heredia 1966-1967: 1, 317-318.

122 CD Salamanca: 321.

123 Se la menciona en 1266 en el deslinde de una bodega "eno mercado de San Martín de Salamanca, so la çapatería», v. CD Salamanca: 318. Recoge el dato González 1944: 1, 488.

124 Beltrán de Heredia 1970-1972: 1, 79. Pedro Pérez consta como deán de Salamanca entre las fechas extremas de 12 de febrero de 1265, v. CD Salamanca: 312 , lo que sugiere que pudo suceder a Domingo Martínez cuando este accedió al obispado de Salamanca en 1264, y de 14 de junio de 1290, v. Ibídem: 430. 
¿SON una SOla y MISMa PeRsona PedRo PÉREZ EL CANCILLER de AlFonso IX de León y Pedro PÉREZ el obisPo de SALAMANCA? HIPÓTESIS EN LUGAR DE CONCLUSIONES

Como anteriormente apuntábamos, el quid de la cuestión consiste en determinar si las dos «unidades biográficas» que hemos analizado por separado corresponden a un único sujeto. Dorado lo asumió de manera acrítica. La cuestión ha sido abordada de manera reflexiva por Julio González y por Vicente Beltrán de Heredia. González considera que, en efecto, el canciller Pedro Pérez es el personaje de este nombre que años después sería obispo de Salamanca y cree que era salmantino por los parientes y heredades asociados a su nombre. ${ }^{125}$ Beltrán de Heredia, en cambio, no piensa que el canciller Pedro Pérez y el obispo Pedro Pérez sean el mismo individuo (aunque reconoce que es posible), básicamente por razón de la edad, y cree que el obispo era gallego por su actuación en el conflicto de intereses entre clero gallego y clero autóctono en el seno del cabildo de Salamanca. ${ }^{126}$

Enfrentados a esa cuestión, lo único que podemos hacer es formular nuevas hipótesis sobre la base de un mayor número de testimonios: no existe, por desgracia, ningún documento concluyente acerca de si el canciller Pedro Pérez y el obispo Pedro Pérez son una sola y misma persona. Nosotros nos inclinamos a pensar que sí. Y ello a partir de los siguientes razonamientos:

En primer lugar, no existe ningún elemento contradictorio que haga irreconciliables ambas «unidades biográficas». Nuestro personaje, después de haber sido canciller de Alfonso IX de León (hasta 1230), pudo seguir haciendo carrera en la iglesia de Orense (hasta 1242), momento en que, por razones que se nos escapan (que, en cualquier caso, debieron de ser de peso, dado lo abrupto de su repentina desaparición de la documentación orensana), hubo de retirarse a sus particulares "cuarteles de invierno" en Salamanca, donde ostentaba desde tiempo atrás una dignidad, donde gozaba de la posesión de bienes y donde finalmente sería promovido al episcopado, que ejercería hasta su renuncia o hasta su muerte en 1264. Como anteriormente apuntábamos, entra dentro de la norma que un individuo que acumula varios beneficios eclesiásticos (canonicatos, arcedianatos, deanatos...) no se titule con todos ellos, sino con el de mayor relevancia según la ocasión. Así, Pedro Pérez, obtenida en primera instancia una dignidad en Salamanca (un arcedianato), la empleó en su titulación como canciller hasta 1221 , pero, obtenida más adelante una dignidad en Orense (la maestrescolía), prefirió emplear esta durante su segundo periodo de desempeño del cargo de canciller (1224-1230), a buen seguro por las razones anteriormente señaladas: su evidente acercamiento a la iglesia de Orense, patente en su presencia en la ciudad en el interregno en que dejó el cargo de canciller (1221-1224), en correspondencia con su aparente distanciamiento de la iglesia de Salamanca, especialmente a partir de la desaparición de su tío el maestrescuela Fruela (1220). Fuera de la cancillería regia, en los documentos dados en las iglesias locales,

125 González 1944: 1, 488-489. Recuérdese, no obstante, que no todos los parentescos que le asigna son ciertos, v. supra nn. 117-118. Lucas Álvarez 1993: 518, no se pronuncia, limitándose a señalar que con posterioridad a su salida de la cancillería regia figura en la documentación orensana como arcediano de su iglesia hasta 1243 (sic).

126 Beltrán de Heredia 1970-1972: 1, 74. Sobre su origen gallego, v. Ibídem: 1, 63, $7073-74$ y 92.
Pedro Pérez empleó la dignidad de las correspondientes iglesias locales. El arcedianato salmantino con el que Pedro Pérez se documenta en $1214-1221$ y ¿1223? puede ser perfectamente el de Medina con el que consta en 1243. En efecto, es extraño que antes de mediados del siglo xIII se exprese el arcedianato concreto que detenta un individuo, por lo que la expresión archidiacono Salamantino con la que Pedro Pérez empezó a titularse en 1214 no debe entenderse como arcediano de Salamanca stricto sensu, sino como arcediano de la iglesia de Salamanca en cualquiera de sus cuatro posibilidades de entonces, aclaradas finalmente por el documento de 1243 que lo presenta como arcediano de Medina. ${ }^{127}$

En segundo lugar, el cursus honorum resultante de considerar al canciller Pedro Pérez y al obispo Pedro Pérez una sola y misma persona es coherente con cuanto se constata en el caso de otros cancilleres del periodo, que veían recompensados sus servicios con beneficios eclesiásticos en las más importantes iglesias del reino, convirtiéndose a menudo en cabeza de las mismas. ${ }^{128}$ En esta dinámica Salamanca jugó un papel especial. ${ }^{129}$ Para alguien como Pedro Pérez, que había desempeñado la cancillería regia durante tantos años, el episcopado era la salida natural, aunque es posible que la extinción del reino privativo de León ralentizase sus aspiraciones. Su destacada presencia en Orense a partir de 1230 parecía ponerlo en la mejor situación para suceder a su prelado Lorenzo cuando acabase su largo episcopado, pero, como anteriormente apuntábamos, algo importante debió de ocurrir en 1242 que movió a Pedro Pérez a dejar Orense en beneficio de Salamanca, donde alcanzaría finalmente el episcopado en unas circunstancias que no eran seguramente las mejores.

En tercer lugar, la edad resultante de considerar al canciller Pedro Pérez y al obispo Pedro Pérez una sola y misma persona es extraordinaria (en efecto, si el primero, que entró al servicio de la cancillería regia en 1203 , hubo de nacer, a más tardar, ca. 1180/85, en su calidad de obispo de Salamanca habría alcanzado la condición de octogenario), pero no es inaceptable. Recordemos, por otra parte, que la bula de Urbano IV de 1261 que restituía al cabildo de Salamanca la futura elección de su obispo se refería a su entonces titular, Pedro Pérez, como grauatus senio, quod de morte dubitabatur ipsius, ${ }^{130}$ afirmación que, aunque puede ser interesada dado que la bula se produce en el contexto del conflicto entre clero gallego y clero autóctono, denota en cualquier caso a un hombre muy mayor a esas alturas, que no creemos que estuviese precisamente ni en sus cincuenta ni en sus sesenta. Beltrán de Heredia recelaba de que en 1247/48 se hubiese nombrado obispo de Salamanca a un hombre que, en el caso de ser efectivamente el canciller, pasaría de los sesenta años, ${ }^{131}$ pero entendemos que las circunstancias en

127 Dorado 1776: 98, dio por hecho, en cambio, que su titulación como arcediano de Salamanca se refería a la dignidad de arcediano de Salamanca stricto sensu, esto es, arcediano de la ciudad y del término de Salamanca.

128 Ese fue el caso, por ejemplo, de Pedro Suárez de Deza, canciller de Fernando II de León, que fue sucesivamente obispo de Salamanca y arzobispo de Santiago de Compostela, así como de Rodrigo Álvarez, que fue obispo de León, o del maestro Bernardo, que fue arzobispo de Santiago de Compostela, v. González 1944: 1, 481-483, 485-486 y 487490; Lucas Álvarez 1993: 512-519.

129 Sánchez y Sánchez 2002: 407-408.

130 V. supra n. 73.

131 Beltrán de Heredia 1970-1972: 1, 74. 
que se produjo su acceso al episcopado justifican esta decisión: el conflicto entre el clero gallego y el autóctono que forzó la redacción de las constituciones del cardenal Gil de Torres en 1245 se llevó por delante, al parecer, al obispo Martín Fernández, que renunció a su sede ese mismo año. ${ }^{132}$ El cabildo salmantino, controlado por el sector gallego, eligió entonces a Fernando Alfonso, hijo ilegítimo de Alfonso IX y deán de Santiago de Compostela, pero el papa, a pesar de recibir, como sabemos, una delegación del cabildo salmantino de la que formaba parte Pedro Pérez en su calidad de arcediano de Medina, no sancionó esta decisión, designando en su lugar a 15 de diciembre de 1246 a uno de sus capellanes (esto es, a un personaje de prestigio al margen de los bandos existentes en el seno del cabildo salmantino), Mateo Reinal, que ocupó la sede durante menos de un año por el ambiente hostil que debió de encontrar en la ciudad, siendo trasladado a Cuenca a 28 de agosto de $1247 . .^{133}$ Fue entonces cuando se eligió a Pedro Pérez, quizás como una solución de compromiso. Por su trayectoria anterior era un personaje incontestable y por su edad avanzada cabía esperar que fuese un obispo "de transición", en tanto se restablecía el equilibrio de fuerzas en el seno del cabildo salmantino bajo la égida del implacable deán, el gallego Domingo Martínez, que figura con extraordinaria potencia desde su primera ocurrencia documental en 1243. Pero Pedro Pérez resultó ser no solo un hombre de edad avanzada, sino también un hombre longevo, de manera que Domingo Martínez tuvo que esperar más de lo que le hubiera gustado para alcanzar el episcopado de Salamanca, que solo pudo disfrutar finalmente durante un breve periodo de tiempo (1264-1268).

Por último, estamos de acuerdo con Beltrán de Heredia en que Pedro Pérez era gallego. Propia de un miembro del clero erudito gallego que tanto ascendiente ejerció sobre la sede salmantina es su carrera en la cancillería regia y en la iglesia de Salamanca junto al hecho de que sus primeros beneficios eclesiásticos documentados sean gallegos: un canonicato en la Catedral de Santiago de Compostela y un canonicato en la Catedral de Orense, y de que mantuviera una especial relación con la iglesia de Orense. Además, insisten en tal procedencia su actuación como obispo denunciando en 1255 las supuestas cartas del fallecido cardenal Gil de Torres que perjudicaban al lobby gallego del cabildo, por más que acabara suscitando la impaciencia de su paisano el deán Domingo Martínez, así como sus inquietudes intelectuales, patentes en su elaborado epitafio, y devocionales, patentes en el programo iconográfico de las pinturas murales que presumiblemente promovió.

\section{Ibídem: 1, 71-72.}

133 Ibídem: 1, 72-73; 4, 521. Beltrán de Heredia pone entre interrogaciones el nombre de Fernando Alfonso pero a la altura de 1245 él era indudablemente el deán de Santiago de Compostela, dignidad en la que consta, cuando menos, desde 1241, estando vacante en 1239, v. Portela Pazos 1944: 99-102. Fernando Alfonso era canónigo de Salamanca, cuando menos, desde 1223, v. CD Salamanca: 156-157, obteniendo finalmente en esta iglesia la dignidad de arcediano de Salamanca, en la que está documentado entre 1266 y 1281, v. Ibídem: $318,321,328,368,375$ y 386. Su muerte, acaecida el 10 de enero de 1286, consta en los obituarios medievales de la Catedral de León, de cuya iglesia era, así mismo, canónigo, v. Herrero Jiménez 1994: 308 (IIII o idus ianuarii (...) obiit domnus Fernandus Alfonsi, filius illustris regis Legionis, decanus Compostellanus et canonicus et subdiaconus huius ecclesie (...) Era $\left.M^{\underline{a}} \operatorname{CCC}^{\underline{a}} X X^{\underline{a}} \| I I I \stackrel{a}{)}\right)$.
En contra de la identificación entre el canciller Pedro Pérez y el obispo Pedro Pérez se puede aducir la brusca desaparición del primero de la documentación orensana en 1242 (indicio acaso de su posible fallecimiento): ciertamente, no encontramos una explicación, satisfactoria o no, para este hecho. Además, el individuo de su nombre que aparece o reaparece en Salamanca en 1243 tiene un perfil diplomático relativamente bajo (lo menciona un único documento con anterioridad a su constancia como obispo de Salamanca en 1248), en abierto contraste con la recurrencia del antiguo canciller Pedro Pérez en la documentación orensana. Siendo esto cierto, no es menos cierto que no se encuentra rastro de Pedro Pérez en el libro de aniversarios de la Catedral de Orense, ${ }^{134}$ lo cual, aunque la casuística de este tipo de repertorios es siempre compleja, sería extraño en un personaje de su potencia que hubiese fallecido allí, y que su escasa presencia en la documentación salmantina de 1243-1248 se puede justificar en parte por su viaje a la curia en compañía de otras dignidades en 1245/46 para gestionar la sucesión del obispo dimisionario Martín Fernández.

En conclusión, a pesar los problemas que suscita el empeño en trazar la biografía de un individuo llamado Pedro Pérez cuyo periplo vital transcurrió en el siglo XIII, pensamos, por las razones expuestas, que es posible que el canciller de Alfonso IX de León Pedro Pérez (1213-1221 y 1224-1230) y el obispo de Salamanca Pedro Pérez (1248-1264) sean una sola y misma persona (ca. 1180/85-ca. 1264), notable por su carrera y por sus iniciativas, a cuyo fundado conocimiento hemos pretendido contribuir con este trabajo.

\section{BiBLIOGRAFÍA}

Aldea Vaquero, Q.; Marín Martínez, T. y Vives Gatell, J. (dirs.) 1972 1975. Diccionario de Historia Eclesiástica de España, 4 t. Madrid: Consejo Superior de Investigaciones Científicas.

Araújo, F. 1884. La reina del Tormes, 2 t. Salamanca: Jacinto Hidalgo, Editor.

Azpeitia Martín, M.a 2007. «El Libro de los aniversarios de la catedral de Salamanca». Salamanca 55: 107-145.

Bango Torviso, I. G. 1992. «El espacio para enterramientos privilegiados en la arquitectura medieval española». Anuario del Departamento de Historia y Teoría del Arte 4: 93-132.

Beltrán de Heredia, V. 1966-1967. Bulario de la Universidad de Salamanca, 3 t. Salamanca: Universidad.

Beltrán de Heredia, V. 1970-1972. Cartulario de la Universidad de Salamanca, 6 t. Salamanca: Universidad.

Berganza, F. de 1721. Antigüedades de España. Parte segunda. Madrid: Francisco del Hierro.

Carrero Santamaría, E. 2005. La catedral vieja de Salamanca. Vida capitular y arquitectura en la Edad Media. Murcia: Nausícaä Edición Electrónica.

Cosmen Alonso, M.a C. 2018. "Gonzalo de Vivero y la catedral de Salamanca», en M. a V. Herráez, M.a C. Cosmen, M.a D. Teijeira y J. A. Moráis Morán (eds.), Obispos y catedrales. Arte en la Castilla bajomedieval - Bishops and Cathedrals. Art in Late Medieval Castile: 33-73. Berna: Peter Lang.

Cuervo, J. (ed.) 1914-1915. Historiadores del convento de San Esteban de Salamanca, 3 t. Salamanca: Imprenta Católica Salmanticense.

Dorado, B. s. a. [1776]. Compendio histórico de la ciudad de Salamanca, Salamanca: Juan Antonio de Lasanta.

Duro Peña, E. 1973. Catálogo de los documentos privados en pergamino del archivo de la catedral de Orense (888-1554). Orense: Instituto de Estudios Orensanos "Padre Feijoo".

\footnotetext{
134 Leirós 1941-1942: 11-35.
} 
Duro Peña, E. 1996. Documentos da catedral de Ourense. Santiago de Compostela: Consello da Cultura Galega.

Eubel, C. 1913. Hierarchia Catholica Medii Aevi, nueva ed. Münster: Libraria Regensbergiana.

Favreau, R. 1979. Les inscriptions médiévales. Turnhout: Brepols.

Fernández Catón, J. M.a 1991. Colección documental del archivo de la catedral de León (775-1230). VI (1188-1230). León: Caja España de Inversiones y Archivo Histórico Diocesano.

Fernández Martínez, C. 2012. «¿Qué aportaron los cristianos a la epigrafía en verso? El caso de Arnolfo (s. IX)». Veleia 29: 29-42.

Fernández Vallina, E. 1999a. "Circuitus mortuorum: personas y noticias lapidarias en las catedrales de Salamanca». Salamanca 43: 25-42.

Fernández Vallina, E. 1999b. «De inscripciones latinas de las catedrales de Salamanca», en V. Bécares Botas, M.a P. Fernández Álvarez y E. Fernández Vallina (eds.), KALON THEAMA. Estudios de Filología Clásica e Indoeuropeo dedicados a F. Romero Cruz: 261-272. Salamanca: Universidad.

Flórez, E. 1762. España Sagrada, t. XVI. Madrid: Imprenta de D. Gabriel Ramírez.

Gams, P. B. (ed.) 1873. Series episcoporum Ecclesiae Catholicae, quotquot innotuerunt a beato Petro apostolo. Ratisbona: Georgh Joseph Manz.

García García, A. 1956. Laurentius Hispanus. Datos biográficos y estudio crítico de sus obras. Roma y Madrid: Consejo Superior de Investigaciones Científicas.

Girón, R. (ed.) 1861. Historia de la ciudad de Salamanca que escribió D. Bernardo Dorado, corregida en algunos puntos, aumentada y continuada hasta nuestros días por varios escritores naturales de esta ciudad. Salamanca: Imprenta del Adelante.

Gómez-Moreno, M. 1967. Catálogo monumental de España. Provincia de Salamanca, 2 t. Valencia: Dirección General de Bellas Artes.

González, J. 1943. Regesta de Fernando II. Madrid: Consejo Superior de Investigaciones Científicas.

González, J. 1944. Alfonso IX, 2 t. Madrid: Consejo Superior de Investigaciones Científicas.

González, J. 1980-1986. Reinado y diplomas de Fernando III, 3 t. Córdoba: Publicaciones del Monte de Piedad y Caja de Ahorros.

González Dávila, G. 1606. Historia de las antigüedades de la ciudad de Salamanca. Salamanca: Imprenta de Artús Taberniel.

González Dávila, G. 1618. Theatro eclesiástico de la iglesia y ciudad de Salamanca. Salamanca: Imprenta de Antonia Ramírez, viuda.

González García, M. 1973. Salamanca: la repoblación y la ciudad en la Baja Edad Media. Salamanca: Centro de Estudios Salmantinos.

González Jiménez, M. y Carmona Ruiz, M.a A. 2012. Documentación e itinerario de Alfonso X el Sabio. Sevilla: Universidad.

Guadalupe Beraza, M.a L.; Martín Martín, J. L.; Vaca Lorenzo, Á. y Villar García, L. M. 2009. Colección documental de la catedral de Salamanca I (1098-1300). León: Caja España de Inversiones y Archivo Histórico Diocesano.

Gutiérrez Baños, F. 2005a. Aportación al estudio de la pintura de estilo gótico lineal en Castilla y León: precisiones cronológicas y corpus de pintura mural y sobre tabla, 2 t. Madrid: Fundación Universitaria Española.

Gutiérrez Baños, F. 2005b. «Un castellano en la corte de Enrique III de Inglaterra: relaciones entre la escuela de Salamanca y el círculo cortesano de Westminster». BSAA arte 71: 13-63.

Gutiérrez Baños, F. 2007. «Imaging the Tomb: Remarks on Funerary Murals of the $13^{\text {th }}$ and $14^{\text {th }}$ Centuries in Castile and Leon", en L. U. Afonso y V. Serrão (eds.), Out of the Stream: Studies in Medieval and Renaissance Mural Painting: $182-205$ y 414-415. Newcastle: Cambridge Scholars Publishing.

Gutiérrez Baños, F. 2011. «Guiños iconográficos en un espacio funerario: las pinturas murales de la capilla de San Martín de la catedral vieja de Salamanca», en R. Alcoy y P. Beseran (eds.), Art i devoció a l'Edat Mitjana (abril del 2008): 45-56. Barcelona: Universidad.

Gutiérrez Baños, F. 2018. «Picturing the Immaculate Conception in Thirteenth-century Castile: The Wall Paintings of the Chapel of San Martín in the Old Cathedral of Salamanca». Iconographica 17: 66-81.
Herrero Jiménez, M. 1994. Colección documental del archivo de la catedral de León. X. Obituarios medievales. León: Caja España de Inversiones y Archivo Histórico Diocesano.

leronimus... 2002. leronimus. 900 años de arte y de historia 1102-2002, catálogo de la exposición (Salamanca, 2002-2003). Salamanca: Cabildo de la Catedral.

Jiménez García, J. Á. 2014. "Restauraciones en las catedrales de Salamanca en los años 50», en M. Casas Hernández (coord.), La catedral de Salamanca. De fortis a magna, actas del Congreso Internacional De fortis a magna: 500 años de historia (Salamanca, 2013): 1761-1798. Salamanca: Diputación.

Lahoz, L. 2014. «Imagen, discurso y memoria en la práctica gótica», en M. Casas Hernández (coord.), La catedral de Salamanca. De fortis a magna, actas del Congreso Internacional De fortis a magna: 500 años de historia (Salamanca, 2013): 233-313. Salamanca: Diputación.

Leirós, E. 1941-1942. «El libro de aniversarios de la catedral de Orense». Boletín de la Comisión Provincial de Monumentos Históricos y Artísticos de Orense 13: 11-35.

Lucas Álvarez, M. 1993. El reino de León en la Alta Edad Media V. Las cancillerías reales (1109-1230). León: Caja España de Inversiones y Archivo Histórico Diocesano.

Marcos Rodríguez, F. 1962. Catálogo de documentos del Archivo Catedralicio de Salamanca. Salamanca: Universidad Pontificia y Consejo Superior de Investigaciones Científicas.

Martín Martín, J. L.; Villar García, L. M.; Marcos Rodríguez, F. y Sánchez Rodríguez, M. 1977. Documentos de los archivos catedralicio y diocesano de Salamanca (siglos XII-XIII). Salamanca: Universidad.

Masdeu, J. F. de 1791. España goda, libro I (Historia crítica de España y de la cultura española, t. IX). Madrid: Imprenta de Sancha.

MLW 1967 y ss. Mittellateinisches Wörterbuch bis zum ausgeheden 13. Jahrhundert. Múnich: C. H. Beck.

Muñoz García de Iturrospe, M. a T. 1995. Tradición formular y literaria en los epitafios latinos de la Hispania cristiana. Vitoria: Universidad del País Vasco.

Pérez Rodríguez, E. 2008. Vita Didaci, poema sobre el fundador de Benevívere. Estudio y edición crítica con traducción del poema y de los diplomas relacionados. León: Universidad.

Portal Monge, Y. 1988. La torre de las campanas de la catedral de Salamanca. Salamanca: Universidad.

Portela Pazos, S. 1944. Decanologio de la S. A. M. Iglesia Catedral de Santiago de Compostela. Santiago de Compostela: Imprenta y Encuadernación del Seminario Conciliar.

Quadrado, J. M.a 1865. Salamanca, Ávila y Segovia (Recuerdos y bellezas de España, vol. XII). Barcelona: Francisco Javier Parcerisa.

Quadrado, J. M.a 1884. Salamanca, Ávila y Segovia (España. Sus monumentos y artes. Su naturaleza e historia). Barcelona: Establecimiento Tipográfico-Editorial de Daniel Cortezo y C.a

Rodríguez Suárez, N. 2017. Salamanca (siglos VIII-XV) (Corpus Inscriptionum Hispaniae Mediaevalium). León: Universidad.

Ruiz Maldonado, M. 2012. «Imágenes de lo sagrado. Imágenes de lo humano. La escultura y pintura medievales», en R. J. Payo Hernanz y V. Berriochoa Sánchez-Moreno (coords.), La catedral de Salamanca. Nueve siglos de historia y arte: 189-254. Burgos: Promecal.

Sánchez Ameijeiras, R. 1993. Investigaciones iconográficas sobre la escultura funeraria del siglo XIII en Castilla y León. Santiago de Compostela: Universidad.

Sánchez y Sánchez, D. 2002. "Catedral y Universidad, una relación secular», en L. E. Rodríguez-San Pedro Bezares (coord.), Historia de la Universidad de Salamanca, vol. I: 404-433. Salamanca: Universidad.

Vaquero Díaz, M.a B. y Pérez Rodríguez, F. J. 2010. Colección documental del archivo de la catedral de Ourense (888-1300), 2 t. León: Caja España de Inversiones y Archivo Histórico Diocesano.

Vicente Bajo, J. A. 1901. Episcopologio salmantino desde la Antigüedad hasta nuestros días. Salamanca: Imprenta de Calatrava.

Villanueva, J. 1850. Viage a Urgel (Viage literario a las iglesias de España, t. XI). Madrid: Imprenta de la Real Academia de la Historia.

Villar y Macías, M. 1887. Historia de Salamanca, 3 t. Salamanca: Imprenta de Francisco Núñez Izquierdo. 